Revista lus et Praxis, Año 21, No 2, 2015, pp. 267 - 316

ISSN 0717 - 2877

Universidad de Talca - Facultad de Ciencias Jurídicas y Sociales

Poder disciplinario del empleador: configuración jurídica de la falta laboral

cometida por el trabajador dependiente

Raúl Fernández Toledo

Trabajo recibido el 1 de marzo y aprobado el 22 de abril de 2015

\title{
Poder disciplinario del empleador: Configuración jurídica de la falta laboral cometida por el trabajador dependiente*
}

DISCIPLINARY POWER OF THE EMPLOYER:

JURIDICAL CONFIGURATION OF PROFESSIONAL MISCONDUCT

COMMITTED BY THE DEPENDENT EMPLOYEE

Raúl Fernández Toledo**

RESUMEN

Mediante el presente trabajo se determinan los requisitos que deben cumplirse para que una conducta del trabajador dependiente pueda ser calificada en forma legítima como falta laboral. Cuestión que es de gran importancia, porque solamente cuando se está en presencia de una falta laboral el empleador puede ejercer lícitamente el poder disciplinario de que está dotado, imponiendo una sanción disciplinaria al trabajador infractor. Es por ello que se establecen los diversos requisitos configuradores de la falta laboral, su contenido y los problemas asociados a la noción de falta laboral, en el contexto del ordenamiento jurídico laboral nacional. De esta forma, el autor realiza una construcción dogmática de la falta laboral en el contexto de la normativa vigente en Chile.

\section{ABSTRACT}

Through the present work there are determined the requirements that must be fulfilled in order that a conduct of the dependent employee can be legitimately qualified as professional misconduct. Issue that is of great importance, because only when we are in the presence of an employment misconduct the employer can lawfully exercise the disciplinary power with which it is provided, by imposing a disciplinary sanction to the offending employee. Therefore, there are established the diverse requirements that configure professional misconduct, its contents and the problems associated with the notion of professional misconduct, in the context of the Chilean legal system. Thus, the author makes a dogmatic construction of professional misconduct in the context of current legislation in Chile.

$$
\text { Palabras Clave }
$$

Poder disciplinario, Falta laboral, Conducta extralaboral, Tipicidad, Culpabilidad

KEY WORDS

Disciplinary power, Professional misconduct, Extra labor conduct, Typicality, Culpability

\footnotetext{
* Abreviaturas: GJ (Gaceta Jurídica); RDJ (Revista de Derecho y Jurisprudencia y Gaceta de los Tribunales); RFM (Revista Fallos del Mes).

** Licenciado en Derecho por la Universidad de Concepción, Magíster en Derecho del Trabajo y Seguridad Social impartido en conjunto por la Universidad de Talca y la Universidad de Valencia. Profesor de Derecho del Trabajo, Facultad de Derecho de la Universidad de Chile. Dirección postal: Facultad de Derecho, Universidad de Chile, Avenida Santa María No 636, Providencia, Chile. Correo electrónico rfernandez@derecho.uchile.cl
} 


\section{Generalidades}

El contrato individual de trabajo se caracteriza por su ejecución de tracto sucesivo, en que el trabajador presta servicios personales al empleador bajo dependencia y subordinación. Con el propósito que el empleador logre que sus trabajadores dependientes ejecuten correctamente las labores encomendadas, mantengan el orden al interior de la organización empresarial y sancione las conductas que constituyen una transgresión de las órdenes, instrucciones u obligaciones que deben observar los trabajadores, se le reconoce por el ordenamiento jurídico el poder disciplinario'. Es en virtud de este poder que puede imponer una sanción al trabajador que ha vulnerado la disciplina laboral, constituyéndose en el garante principal de la efectividad del poder de dirección de que, también, está dotado el empleador². Esto porque, si no existiera la posibilidad que el empleador pudiera sancionar a los trabajadores que con su conducta infringen las órdenes e instrucciones que les imparte, el poder de dirección sería un mero poder moral, al no poder el empresario castigar su transgresión o tener la posibilidad de ello ${ }^{3}$. Es por eso que el poder disciplinario asegura y garantiza la efectividad del ejercicio del poder de dirección, al permitir al empleador asegurar jurídicamente su autoridad y el cumplimiento de sus órdenes y mandatos, con el objeto de alcanzar el interés de la empresa.

La posibilidad de imponer sanciones por el empleador ha sido reconocida expresamente por diversas normas del Código del Trabajo y su legislación complementaria. Es así, que el artículo 160 del Código del Trabajo reconoce al empleador el derecho a llevar a cabo el despido disciplinario en contra de los trabajadores que incurren en ciertas faltas laborales graves, extinguiéndose el contrato individual de trabajo sin derecho a indemnización. Por su parte, el artículo $154 \mathrm{~N}^{\circ} 10$ del mismo Código establece que el empleador puede sancionar con amonestación escrita, amonestación verbal o multa de hasta el veinticinco por ciento de la remuneración diaria al trabajador que vulnera las obligaciones y/o prohibiciones establecidas en el reglamento interno de orden, higiene y seguridad. La Ley No 16.744 sobre Accidentes del Trabajo y

\footnotetext{
1 Lizama (2003), p. 80.

2 Fernández (2014), p. 136.

3 Olea y CASAS (2006), sostienen: "El poder de dirección sería un mero poder moral si no estuviera acompañado de sancionar los incumplimientos a las órdenes generales o especiales del empresario. A esto es a lo que se denomina poder sancionador, o en terminología más generalizada, poder disciplinario. Este poder es del empresario, como correlato de su poder de dirección y del auténtico deber de obediencia que genera en el trabajador". En términos similares: TeRrADILlos (2004), p. 16; Fernández -Costales (2005), p. 39; Rodríguez (2008), pp. 15-19.
} 
Enfermedades Profesionales en su artículo $67^{4}$ legitima la facultad del empleador de imponer multas a los trabajadores que no cumplen con las normas de higiene y seguridad en el trabajo, remitiéndose para ello al título del Código del Trabajo que regula el reglamento interno.

Debido a que en el poder disciplinario existen intereses diversos involucrados, el interés del empresario -titular del mismo- y los intereses de los trabajadores afectados con su ejercicio, aquél se encuentra sujeto a diversos límites, en las diversas fases que comprende su ejercicio. En una aproximación temporal cronológica del ejercicio del poder disciplinario es posible encontrar tres etapas trascendentales: la de la determinación de la conducta sancionable, constituida por la falta laboral, la de la fijación de la sanción a imponer y la de la imposición de la sanción ${ }^{5}$. Cada una de ellas tiene límites y requisitos que deben ser observados por el empleador si desea que la sanción impuesta al dependiente cumpla su función y no sea cuestionada, si es impugnada por el trabajador afectado.

Tratándose de la falta laboral, es el presupuesto desencadenante del ejercicio del poder disciplinario o, si se prefiere, el objeto de las correcciones en que se materializa dicho poder ${ }^{6}$. Si no se configura aquélla no resulta posible ejercer el poder disciplinario, al carecer de causa y, de ejercerse, deberá sancionarse de acuerdo al ordenamiento jurídico vigente, por haberse materializado ilegítimamente. Es por ello que es relevante determinar cuándo se está en presencia de una falta laboral. De ahí, que en la presente investigación se responde a la pregunta de ¿cuáles son los requisitos que debe cumplir una conducta del trabajador dependiente para que pueda ser calificada de falta laboral? Pregunta de la cual surgen una serie de preguntas específicas, destacando las siguientes: ¿es necesario una determinación previa de las conductas que puede sancionar el

${ }^{4}$ Dispone este artículo: "Las empresas o entidades estarán obligadas a mantener al día los reglamentos internos de higiene y seguridad en el trabajo y los trabajadores a cumplir con las exigencias que dichos reglamentos les impongan. Los reglamentos deberán consultar la aplicación de multas a los trabajadores que no utilicen los elementos de protección personal que se les haya proporcionado o que no cumplan las obligaciones que les impongan las normas, reglamentaciones o instrucciones sobre higiene y seguridad en el trabajo. La aplicación de tales multas se regirá por lo dispuesto en el Párrafo I del Título III del Libro I del Código del Trabajo". El artículo 20 del Decreto Supremo No 40, del Ministerio del Trabajo y Previsión Social, refiriéndose al reglamento de higiene y seguridad en el trabajo, dispone "el reglamento contemplará sanciones a los trabajadores que no lo respeten en cualquiera de sus partes. Las sanciones consistirán en multas en dinero que serán proporcionales a la gravedad de la infracción, pero no podrán exceder de la cuarta parte del salario diario y serán aplicadas de acuerdo con lo dispuesto en el artículo 153 del Código del Trabajo. Estos fondos se destinarán a otorgar premios a los obreros del mismo establecimiento o faena, previo el descuento de un $10 \%$ para el fondo destinado a la rehabilitación de alcohólicos que establece la Ley No 16.744".

${ }^{5}$ FeRnÁNDEZ (1991), p. 153.

${ }^{6}$ Castro (1993), p. 117; Terradillos (2004), p. 27. 
empleador?, en la afirmativa, ¿quiénes son los sujetos legitimados para realizar esta tipificación previa?, ¿cuáles son los instrumentos en que debe realizarse la tipificación de las conductas que pueden sancionarse por el empleador?, ¿qué requisitos debe cumplir la tipificación previa de las conductas sancionables?, ¿qué tipos de comportamientos del trabajador pueden sancionarse?, ¿solamente los observados en la ejecución de la prestación laboral o también conductas extralaborales?, ¿es la culpabilidad un elemento integrante de la falta laboral?, $\mathrm{o}$, por el contrario, ¿ésta solamente tiene incidencia en la graduación de la falta laboral? ¿cuál es la relación entre una conducta que simultáneamente da lugar a un incumplimiento laboral y a un ilícito penal? Todos problemas que se responden en el presente trabajo.

Para lograr los objetivos propuestos, se recurrió a las fuentes normativas y bibliográficas ${ }^{7}$. También se acudió a la jurisprudencia judicial ${ }^{8}$ y administrativa ${ }^{9}$, que si bien no es fuente formal del derecho en nuestro ordenamiento jurídico, tiene una trascendencia fundamental en la construcción dogmática de la falta laboral, debido a que es abundante, especialmente respecto del despido disciplinario. De esta forma, de pronunciamientos particulares realizados por los Tribunales de Justicia en juicios donde se ha impugnado el despido disciplinario de que han sido objeto los trabajadores, se extraen elementos que sirven para establecer cuál es la configuración de falta laboral ${ }^{10}$ existente en el Derecho del Trabajo chileno.

\footnotetext{
7 Especialmente se recurrió a las investigaciones que los autores nacionales han realizado sobre el poder disciplinario o sobre una de las etapas del mismo, sea en monografías, obras de derecho colectivo, como también en artículos publicados en revistas especializadas. Por su parte, la doctrina extranjera se utilizó como argumento de refuerzo en forma recurrente, debido a que han sido los autores extranjeros quienes han tratado en numerosos trabajos de investigación al poder disciplinario empresarial, utilizándose especialmente obras de autores españoles e italianos y algunas de autores franceses y uruguayos.

${ }^{8}$ Se ha considerado como universo de estudio las sentencias de los Tribunales de Justicia, es decir, de los Juzgados del Trabajo y de los Juzgados Civiles con competencia en lo laboral, de las Cortes de Apelaciones del país y de la Corte Suprema, que hayan sido publicadas a partir del año 1980 en las revistas especializadas a saber: Revista de Derecho y Jurisprudencia, Revista Fallos del Mes y Gaceta Jurídica. A este universo de estudio se plantean tres excepciones. Primero, debido a que no todas las sentencias de la Corte Suprema y de las Cortes de Apelaciones se publican en revistas especializadas, su revisión también se ha efectuado a través de la página web del Poder Judicial. En segundo lugar, la revisión de las sentencias judiciales pronunciadas por los tribunales del país indicados desde el año 2000 se ha efectuado, igualmente, a través de los buscadores electrónicos Microjuris y Legal Publishing. $\mathrm{Y}$ tercero, se consideraron sentencias judiciales cuyo conocimiento se ha obtenido a consecuencia del ejercicio de la profesión.

${ }^{9}$ Se consideran los dictámenes emanados de la Dirección del Trabajo desde el año 1990, pronunciados sobre el poder disciplinario, sea directamente o de forma implícita, publicados en la página web de la Dirección del Trabajo.

${ }^{10}$ Las expresiones "falta laboral", "incumplimiento laboral" e "infracción laboral" se emplearán indistintamente en el presente trabajo, considerándose sinónimas.
} 


\section{Aproximación a la noción de falta laboral}

No existe ninguna norma legal ni reglamentaria en el ordenamiento jurídico laboral nacional que defina la falta laboral en que puede incurrir el trabajador, que habilita al empleador ejercer el poder disciplinario mediante la imposición de una sanción. Indefinición que no es ajena en el derecho comparado, donde tampoco se encuentra un concepto de falta laboral. De ahí, que la doctrina extranjera defina la infracción laboral desde un punto de vista meramente descriptivo, situación que no existe en la doctrina nacional, donde no hay un concepto de falta laboral. Así, en la doctrina extranjera se encuentran definiciones, como aquellas que sostienen que "la falta disciplinaria supone la violación injustificada de una obligación profesional lícitamente impuesta"11 $\mathrm{o}$, bien, que la falta laboral constituye "una acción u omisión cometida conscientemente por el trabajador en violación de los deberes que le incumben en base al contrato de trabajo"12. También, se han definido las faltas laborales como "las acciones u omisiones punibles que supongan una infracción o incumplimiento de los deberes laborales del trabajador, consignadas en los convenios y en las leyes de trabajo vigentes, siempre y cuando se cometan con la intención de infringir o con mera negligencia"1 ${ }^{13}$.

Debido a que todas las definiciones antes expuestas han sido formuladas por la doctrina española, italiana y francesa tomando en consideración las circunstancias particulares de la legislación vigente en los ordenamientos jurídicos respectivos no son trasladables per se al ordenamiento jurídico laboral chileno. Esto porque cada ordenamiento jurídico tiene particularidades propias, no quedando al margen el poder disciplinario del empleador y, por lo mismo, tampoco el concepto de falta laboral, que constituye el presupuesto de ejercicio del poder disciplinario.

Ante la omisión en que incurre el legislador nacional, al no contener una definición de falta laboral, resulta necesario acudir a las normas del Código del Trabajo y otras normas especiales que se identifican como fuentes reguladoras de la materia, además, de recurrir a la doctrina extranjera que sirva de apoyo para formular un concepto de falta laboral. En efecto, destacan diversas normas laborales. Es así, que los artículos 153, 154 números 5 y 9 del Código del Trabajo, que regulan el contenido del reglamento interno de orden, higiene y

\footnotetext{
11 Camerlynck et al. (1984), p. 425. En igual sentido: Fernández - Costales (2005), p. 46.

12 Lega (1956), p. 205.

${ }^{13}$ CAStro (2003), pp. 118-119. En similares términos Poquet, para quien la falta laboral es "el incumplimiento de cualquier obligación impuesta a los trabajadores, por las normas legales o convencionales, o asumidas por éstos en el contrato individual", Poquet (2011), p. 113. Por su parte, SANTANa señala: "Constituye falta disciplinaria la acción u omisión que suponga una infracción o incumplimiento de las obligaciones laborales del trabajador", SANTANA (2001), p. 61.
} 
seguridad, determinan que el mismo debe contener las obligaciones y prohibiciones a que deben sujetarse los trabajadores de la empresa, en relación con sus labores, permanencia y vida en las dependencias de las respectiva empresa o establecimiento. Por su parte, el artículo 154 № 10 del Código del Trabajo establece las sanciones que puede contemplar el reglamento interno y que puede aplicar el empleador a los trabajadores que incurren en infracciones a las obligaciones y prohibiciones contempladas en el mismo; el artículo 160 del Código del Trabajo señala las causales del despido disciplinario; los artículos $6^{\circ}, 303,344$ inciso $2^{\circ}$ y 351 del Código del Trabajo disponen que el objeto de los instrumentos colectivos de trabajo es establecer condiciones comunes de trabajo para las trabajadores sujetos al mismo. El artículo 67 de la Ley $N^{\circ} 16.744$ señala que las órdenes e instrucciones a que deben sujetarse los trabajadores en materia de seguridad deben contenerse en el reglamento de higiene y seguridad en el trabajo. Artículo, este último, que es complementado con el Decreto Supremo No 40, del Ministerio del Trabajo y Previsión Social, que establece las exigencias del reglamento de higiene y seguridad en el trabajo ${ }^{14}$, disponiendo que debe contener dicho reglamento las obligaciones (artículo 18) y prohibiciones (artículo 19) que deben observar los trabajadores en materia de higiene y seguridad en el trabajo. Finalmente, existen normas especiales que rigen en actividades económicas específicas, destacando los artículos 38, 39, 40 y 41 del Reglamento de Seguridad Minera (Decreto Supremo № 132, del Ministerio de Minería, de 2004).

Teniendo presente lo dispuesto en las normas legales indicadas, es posible dar un concepto preliminar de falta laboral, señalando que constituye la conducta observada por el trabajador dependiente que provoca la transgresión de alguna obligación o prohibición consignada previamente en el contrato individual de trabajo, en el reglamento interno, en el reglamento de higiene y seguridad en el trabajo, en el instrumento colectivo de trabajo o en las normas laborales vigentes emanadas del Estado, sea con la intención de infringir o con mera negligencia.

Se dice que es un concepto preliminar, porque debe demostrarse si el mismo se ajusta a las exigencias que la legislación laboral nacional vigente establece para la configuración de un incumplimiento laboral sancionable. No obstante ello, lo que sí resulta claro es que para estar en presencia de una falta laboral deben infringirse por el trabajador dependiente obligaciones o prohibiciones que deben estar establecidas previamente en ciertos instrumentos que señala la normativa laboral.

14 Dispone el artículo 16 del Decreto Supremo № 40: "El reglamento deberá comprender como mínimo un preámbulo y cuatro capítulos destinados respectivamente a disposiciones generales, obligaciones, prohibiciones y sanciones". 


\section{Tipificación previa de las conductas del trabajador dependiente sancionables por el empleador}

Debido a que el ejercicio del poder disciplinario constituye un acto de autotutela privada ${ }^{15}$, el reconocimiento de la posibilidad concreta de aplicar por el empleador una sanción a sus trabajadores por transgresión a la disciplina laboral ha de provenir de la ley o de una fuente a que se remita la ley ${ }^{16}$. Esto significa que constituye un presupuesto indispensable de su ejercicio la determinación previa, en forma abstracta, no sólo de las sanciones que puede aplicar el empleador, sino también de las obligaciones y prohibiciones cuya transgresión por el dependiente configuran un incumplimiento laboral.

Al ser el Código del Trabajo -que contiene disposiciones de rango legal-el cuerpo normativo que reconoce expresamente el poder disciplinario del empleador, surge como primera duda si la tipificación de la conducta que deben observar los trabajadores necesariamente debe ser realizada por disposiciones jurídicas de jerarquía legal, al igual que ocurre con los ilícitos penales, según lo ordena el artículo $19 \mathrm{~N}^{\circ} 3$ inciso $9^{\circ}$ de la Constitución Política de la República ${ }^{17}$. Posibilidad que necesariamente debe rechazarse desde el momento en que se reconoce que el poder sancionador empresarial es un derecho subjetivo de orden jurídico privado que nada tiene que ver con el ius puniendi del Estado ${ }^{18}$. Atendido el tenor literal del artículo $19 \mathrm{~N}^{\circ} 3$ inciso $9^{\circ}$ de la Constitución Política de la República no cabe duda que la vigencia del principio de legalidad formal aparece referido a los delitos, que son sancionados por órganos del Estado, cuyo castigo protege intereses generales de la sociedad; característica que no existe en los incumplimientos laborales sancionables, ni en las sanciones con que el empleador castiga los mismos, las que tienen carácter privado ${ }^{19}$.

Sin embargo, debido a que en virtud del ejercicio del poder disciplinario se imponen verdaderas penas privadas ${ }^{20}$ no se niega la vigencia del principio de legalidad en su vertiente material, es decir, del principio de tipicidad, conforme

${ }^{15}$ Gil (1993), p. 36; RodríGuez (2008), pp. 14-15.

16 GIL (1993), p. 36.

17 Dispone esta norma: "Ninguna ley podrá establecer penas sin que la conducta que se sanciona esté expresamente descrita en ella".

${ }^{18}$ Cruz (2010), p. 219: "la afirmación del carácter privado del poder disciplinario conduce a la conclusión de que no pueda pretenderse aplicar mecánicamente las garantías del ejercicio de los poderes sancionadores públicos. En particular, ello comporta que el trabajador no puede reclamar el respeto a los condicionantes del ejercicio de la sanción pública impuestos constitucionalmente".

19 Castro (1993), pp. 56-58; Terradillos (2004), pp. 31-32.

20 Sobre la consideración de las sanciones laborales como penas privadas véase, especialmente: Monstuschi (1991), p. 21; Fernández (1991), pp. 236-237; Mainardi (2002), p. 170; Di Paola (2010), pp. 13-14; Mazzotta (2011), p. 540; RodríGuez (2008), p. 183; Mainardi (2012), p. 92. 
al cual los hechos sancionables en el ámbito laboral deben encontrarse previamente tipificados ${ }^{21}$. De este modo, sólo podrán sancionarse por el empleador los comportamientos que se encuentren previamente descritos, aun en forma genérica en la ley o en los instrumentos a que la misma se remita ${ }^{22}$. De no estar determinadas previamente las obligaciones y prohibiciones laborales que deben observar los trabajadores no se puede configurar la falta laboral ${ }^{23}$.

El fundamento de la aplicación del principio de tipicidad en el ámbito del poder disciplinario empresarial no sólo emana de su naturaleza de principio general del derecho imperante en todos los poderes punitivos de que están dotados ciertos sujetos de derecho público o derecho privado, cuyo ejercicio permite aplicar penas públicas o privadas ${ }^{24}$, sino también, en que la propia normativa laboral reconoce su vigencia en diversas normas contenidas en el Código del Trabajo. Ahora bien, el principio de tipicidad en materia de predeterminación de incumplimientos laborales y de normas de conducta cuya transgresión genera una falta laboral no está exento de dificultades, generando diversas dudas, siendo dos las principales.

La primera cuestión consiste en determinar cuáles son los instrumentos en que deben tipificarse las normas de conducta que rigen el actuar del trabajador, cuya infracción puede legítimamente sancionar el empleador. La que, a su vez, plantea el problema de saber qué papel corresponde al empleador en la individualización de las faltas laborales, de las obligaciones y prohibiciones que deben cumplir los trabajadores. Ello implica resolver si el empleador es el único legitimado para determinar ex-novo qué conductas deben ser sancionadas y cuáles no o, por el contrario, comparte esa facultad con la parte trabajadora, sean los trabajadores individualmente considerados o en forma colectiva.

En la doctrina parece prevalecer la idea de que es el empleador el sujeto naturalmente legitimado para individualizar las infracciones laborales ${ }^{25}$. Ello porque a diferencia de lo que ocurre en el Derecho Penal, donde el sujeto que sanciona no es el mismo que determina qué hechos han de ser sancionados, función que en los Estados Democráticos corresponde al legislador, en el poder disciplinario del empleador la situación es distinta. El ordenamiento jurídico

21 Cremades (1969), pp. 170-172; Fernández (1991), pp. 155-115; Castro (1993), p. 59; Gil (1993), pp. 37-41;Carcelén (2001), pp. 31-34; Terradillos (2004), pp. 31-32; Fernández-Costales (2005), p. 56; Olea y Casas (2006), p. 442; Sagardoy et al. (2006), p. 209; Cruz (2010), p. 221; Poquet (2011), pp. 4749; MAZZOTTA (2011), p. 545.

22 Carcelén (2001), p. 33; Fernández (2014), p. 152.

${ }^{23}$ Corte de Apelaciones de Iquique, Rol Reforma Laboral Nº 68-2014, 16 de enero de 2015.

24 Fernández (1991), p. 153; Castro (1993), p. 58; Gil (1993), p. 37; Rodríguez (2008), p. 37; Poquet (2011), pp. 47-49.

25 Fernández (1991), p. 159; Poquet (2011), p. 46. 
confiere al empleador facultades punitivas para el mantenimiento del orden productivo en la empresa ${ }^{26}$, que le permite seleccionar las conductas contrarias a los intereses de la empresa y, que merecen una sanción aplicada por él mismo. De este modo, en el poder disciplinario existe una inmediación estructural entre las facultades que derivan del mismo y el sujeto que las ejerce, "inmediación que se conecta con la defensa del interés de ese sujeto, porque en su misma mano se depositan su determinación y defensa; de ahí que aparezca como particularmente legitimado el titular de ese interés para concretar cómo y cuándo ha sido lesionado, y para poner en marcha los mecanismos adecuados para su defensa" ${ }^{\prime 27}$. Esta unidad básica que existe entre el empleador, su interés y las medidas de defensa de ese interés, es la que justifica que "el sujeto que sanciona puede ser el mismo que individualiza los hechos que han de ser sancionados" ${ }^{\prime 28}$.

Ahora bien, para que el poder disciplinario exista y pueda ser reconocido como tal, no es necesario que el empleador y solamente él sea quien determine qué hechos han de ser sancionados. Es así, que el contrato individual de trabajo y la negociación colectiva pueden imponer obligaciones y prohibiciones a los trabajadores que son parte de los mismos, compartiendo el empleador una de las fases del poder disciplinario: el de la determinación de las conductas sancionables, más no el de la imposición de la sanción (artículo 306 inciso $2^{\circ}$ del Código del Trabajo).

La decisión de imponer una sanción al trabajador infractor y la imposición misma se han reservado exclusivamente al empleador, formando parte de lo que podríamos denominar "Orden Público Laboral". El que sea el empleador quien determine si ejerce o no su facultad sancionadora para la defensa de su interés es un rasgo definitorio de todo derecho subjetivo potestativo -carácter que tiene el ejercicio del poder disciplinario ${ }^{29}-$ y no podría negarse al empleador su ejercicio, porque se negaría el derecho mismo. Pero la atribución exclusiva del ejercicio del poder disciplinario al empresario no significa necesariamente el dominio por parte del empleador de todas las fases del mecanismo sancionador $^{30}$. El poder disciplinario sigue cumpliendo su función cuando la fase de determinación de las conductas sancionables es compartida por los sujetos de la relación laboral y se atribuye al empleador en forma exclusiva la fase de imposición o no de una sanción al trabajador infractor. Y esto es así, porque la naturaleza de autotutela privada del ejercicio del poder disciplinario no queda

\footnotetext{
${ }^{26}$ Cremades (1969), p. 172.

27 Fernández (1991), p. 160.

${ }^{28}$ FeRNÁNDEZ (1991), p. 160.

${ }^{29}$ GIL (1991), p. 33.

30 Spagnuolo (1972), pp. 50 ss.; Fernández (1991), p. 161.
} 
desconocida cuando en la fase de determinación de las conductas sancionables intervienen terceras personas, por el contrario, revela que dicho poder queda sometido cada vez más a mayores controles técnicos.

La segunda cuestión está vinculada al problema de determinar con qué estándar deben tipificarse los comportamientos, las obligaciones y prohibiciones que debe observar el trabajador, esto es, cómo debe realizarse la individualización de las conductas sancionables. Lo que revela la necesidad de conocer cuál es el nivel de precisión con que dichas conductas deben ser individualizadas y, sobre todo, en qué momento. Circunstancia que genera la duda sobre si las conductas que configuran faltas laborales deben estar previamente determinadas en todas sus circunstancias para poder sancionarlas el empleador o, por el contrario, el empleador puede caso por caso decidir si una conducta a la luz de las circunstancias concurrentes puede ser calificada de falta laboral ${ }^{31}$.

\subsection{Cuerpos normativos en que deben tipificarse las conductas sancionables}

Resulta claro que no rige en materia disciplinaria empresarial el principio de legalidad formal propio del Derecho Penal, que según definición constitucional consagra las garantías de "ningún delito sin ley" y "ninguna sanción sin ley", debido a que la ley no se ocupa de tipificar las faltas y sanciones laborales, o al menos no exclusivamente, encomendando, también, a otros cuerpos normativos esta labor, debiéndose determinar cuáles son los mismos. Al examinarse el Código del Trabajo se puede observar que el mismo no sólo establece algunas faltas laborales sino que también atribuye competencia para determinar las conductas sancionables al reglamento interno, a la negociación colectiva y al contrato individual de trabajo, esto es, Ileva a cabo una atribución de titularidad de la facultad de determinar las conductas sancionables, encomendándosela no sólo al empleador exclusivamente sino también a éste en conjunto con los trabajadores, individual o colectivamente considerados, debiéndose determinar los instrumentos a través de los cuales debe realizarse esa individualización:

a) La ley. Las normas legales no solamente otorgan cobertura a otros cuerpos normativos y reglamentarios para predeterminar las conductas sancionables, sino que también establecen algunas faltas laborales. Es así, que el Código del Trabajo en el artículo 160 establece una enumeración de las faltas laborales, esto es, de los comportamientos del trabajador que justifican la aplicación y materialización del despido disciplinario. Analizada esta norma, se observa que contiene una enumeración de incumplimientos laborales graves, que vulneran

31 Fernández (1991), pp. 157-159. 
los deberes básicos del trabajador que contemplan el Código del Trabajo y el contrato de trabajo.

El artículo 160 del Código del Trabajo no contiene una lista cerrada de incumplimientos laborales, pese a la aparente intención de su encabezado. Debido a la amplitud con que se hallan mencionadas en este precepto algunas de las causas del despido disciplinario, especialmente la del $\mathrm{N}^{0} 7$, es bizantina la discusión acerca del carácter cerrado, tasado o ejemplar del listado que contiene dicho precepto. Incluso más, el legislador se podría haber ahorrado la enumeración de faltas laborales que permiten aplicar el despido disciplinario debido a la amplios términos en que se encuentra formulada la causal del $N^{\circ} 7$ del artículo 160 del Código del Trabajo. Este precepto está redactado con una amplitud suficiente para comprender las restantes causas de despido disciplinario ${ }^{32}$.

$\mathrm{Al}$ ser las normas legales que rigen la terminación del contrato individual de trabajo absolutamente imperativas ${ }^{33}$, las partes por medio de la autonomía individual o colectiva no pueden alterar dicha determinación, no pudiendo agregar nuevas causales que tipifiquen faltas laborales que permitan extinguir el contrato individual de trabajo a través del despido disciplinario ni suprimir las existentes. Tampoco el empleador puede alterar unilateralmente las causales o agregar nuevas causales a través del reglamento interno de orden, higiene y seguridad ${ }^{34}$, del código de conducta u otro cuerpo normativo interno.

b) El reglamento interno y el reglamento de higiene y seguridad en el trabajo. No debe pasarse por alto que el titular del poder disciplinario es el empleador, es a él a quien la legislación le ha reconocido dicho poder, siendo una emanación natural del contrato de trabajo ${ }^{35}$. Si bien el empresario en el ordenamiento jurídico nacional no es el único sujeto legitimado para determinar ex-novo qué conductas deben ser sancionadas y cuáles no, compartiendo esta facultad junto a otros sujetos de derecho ${ }^{36}$, es el sujeto más naturalmente legitimado para individualizar las conductas que puede sancionar. Esto porque el ordenamiento jurídico concede facultades punitivas al empleador para el mantenimiento del orden en la empresa, asegurando el correcto desarrollo de la actividad productiva de que es titular y la debida convivencia entre los trabajadores que emplea. Si el empleador es el titular del poder de dirección en razón del cual puede

\footnotetext{
32 Para una discusión similar en el Derecho Español véase: Olea y CASAS (2006), pp. 515-516.

33 Las normas absolutamente imperativas impiden la negociación colectiva y la contratación individual sobre las materias por ellas reguladas. Véase sobre la materia: SALA (2003), pp. 127-137.

34 Gamonal y Guidi (2012), p. 251.

35 Se señala que "al igual que ocurre con el poder de dirección, el disciplinario tiene su fuente jurídica inmediata en la celebración del contrato de trabajo, y su origen mediato en la voluntad de la ley", MONTOYA (2014), p. 369.

36 Fernández (1991), p. 139.
} 
organizar la producción e impartir instrucciones a los trabajadores, es natural que se concedan los instrumentos necesarios para singularizar las conductas que atentan contra el poder de dirección. De ahí, que resulta natural la legitimación del titular del interés en la organización productiva "para concretar cómo y cuándo ha sido lesionado, y para poner en marcha los mecanismos adecuados para su defensa" ${ }^{\prime 37}$.

El instrumento de que dispone el empleador para tipificar tanto las infracciones laborales como las obligaciones y prohibiciones cuya transgresión por los trabajadores configuran una infracción laboral es el reglamento interno ${ }^{38}$. Así lo demuestran los artículos 153 y 154 del Código del Trabajo. El artículo 153 inciso $1^{\circ}$, establece en lo pertinente"Las empresas [...] estarán obligadas a confeccionar un reglamento interno de orden, higiene y seguridad que contenga las obligaciones y prohibiciones a que deben sujetarse los trabajadores, en relación con sus labores, permanencia y vida en las dependencias de la respectiva empresa o establecimiento". Por su parte, el artículo 154 señala "El reglamento interno deberá contener, a lo menos, las siguientes disposiciones: [...] 5. Las obligaciones y prohibiciones a que estén sujetos los trabajadores. [...] 9. Las normas e instrucciones de prevención, higiene y seguridad que deban observarse en la empresa o establecimiento".

El reglamento interno es elaborado unilateralmente por el empresario, siendo su confección obligatoria en empresas que ocupan normalmente 10 o más trabajadores (artículo 153 inciso $1^{\circ}$ del Código del Trabajo), y facultativo cuando se ocupan menos de esa cantidad de trabajadores ${ }^{39}$. El delegado de personal, cualquier trabajador o las organizaciones sindicales solamente pueden impugnar las disposiciones del reglamento que consideren ilegales mediante presentación efectuada ante la autoridad competente, sin perjuicio que las mismas de oficio exijan modificar las disposiciones que se estimen ilegales (artículo 153 inciso final del Código del Trabajo), pero no pueden ellos mismos realizar las modificaciones, facultad solamente reservada al empleador.

\footnotetext{
37 FERNÁNDEZ (1991), p. 160.

${ }^{38}$ Si bien la doctrina considera que el reglamento interno es manifestación del poder de reglamentación del empleador (en este sentido Gamonal y Guidi (2012), pp. 96-100), nada impide que en el mismo se establezca una tipificación de las faltas laborales como también de las obligaciones y prohibiciones que deben observar los trabajadores cuya transgresión configura una falta laboral, la que es presupuesto del ejercicio del poder disciplinario, que es otro poder del empleador. Tanto el poder de reglamentación como el poder de disciplinario forman parte del poder de dirección en sentido amplio, interrelacionándose frecuentemente. Véanse en este sentido los siguientes dictámenes de la Dirección del Trabajo: Dictamen N N 2.084/104 de 17 de abril de 1987, Dictamen № 3.659/0180 de 2 de octubre de 2001, Dictamen No 2.856/162 de 30 de agosto de 2002, Dictamen No 2.010/035 de 10 de junio de 2009, Dictamen № 5.073/082 de 16 de diciembre de 2014.
}

39 Macchiavello (1986), p. 251. 
Conjuntamente con el reglamento interno, se encuentra el reglamento de higiene y seguridad en el trabajo ${ }^{40}$, que deben elaborar las empresas independientemente del número de trabajadores que ocupen, en el cual deben contenerse las obligaciones y prohibiciones que debe observar el trabajador en materia de higiene y seguridad en el trabajo (artículo 67 de la Ley $\left.\mathrm{N}^{0} 16.744\right)^{41}$. Generalmente el reglamento interno y el reglamento de higiene y seguridad en el trabajo, no obstante ser distintos, se contienen en el mismo documento ${ }^{42}$.

Según se puede observar, las normas de conducta que deben establecer el reglamento interno y el reglamento de higiene y seguridad en el trabajo adoptan esencialmente la forma de obligaciones y prohibiciones a que deben sujetarse los trabajadores en relación a sus labores, permanencia, vida, higiene y seguridad en la empresa. Por tanto, su vulneración configura una falta laboral. Ello sin perjuicio que el reglamento interno pueda legítimamente tipificar en abstracto faltas laborales cuya configuración en el caso concreto puede sancionar el empleador, no existiendo norma que impida esta posibilidad en la legislación laboral43.

c) La negociación colectiva y el contrato individual de trabajo. El empleador y la ley no son los únicos legitimados para establecer las conductas que pueden ser sancionadas, también lo puede realizar el empleador en conjunto con el trabajador al celebrar el contrato individual de trabajo o con un conjunto de trabajadores o con un sindicato si celebra un instrumento colectivo de trabajo, existiendo, por tanto, una titularidad compartida en la singularización de las conductas que pueden ser sancionadas.

Tratándose del contrato individual de trabajo, es posible la concertación de común acuerdo por las partes de las obligaciones y prohibiciones a que se sujetará el trabajador durante el desarrollo de la relación laboral. El artículo 160 NN$^{\circ} 7$ del Código del Trabajo es la disposición legal que otorga competencia

\footnotetext{
${ }^{40}$ Las exigencias del reglamento de higiene y seguridad en el trabajo se encuentran establecidas en el Decreto Supremo № 40, del Ministerio del Trabajo y Previsión Social, de 1969.

${ }^{41}$ Lanata (2010), p. 43; Gamonal y Guidi (2012), p. 100. En el mismo sentido: dictamen de la Dirección del Trabajo № 2.680/127 de 17 de julio de 2001.

42 Melisy SÁez (2009), pp. 625-626: “Es del caso señalar que si bien el Reglamento de Orden, Seguridad e Higiene y el Reglamento de Higiene y Seguridad son instrumentos distintos, que regulan cada uno cuestiones específicas; uno, la ordenación del trabajo y, el otro, las normas sobre seguridad y salud en el centro de trabajo, parece razonable entender, como lo ha hecho la Dirección del Trabajo, que cuando exista la obligación de tener ambos reglamentos, se cumple con dicha obligación al integrarlos en un solo texto que contenga toda la regulación".

${ }^{43}$ Se ha sostenido que "el reglamento delimita lo que puede hacer cada trabajador, en el marco de la organización. Al respecto, se establecen qué hechos del trabajador se consideran faltas, el procedimiento de comprobación, la defensa, las sanciones, los recursos. O sea, en este punto, el empleador reglamenta sus facultades disciplinarias", MACCHIAVELlo (1986), p. 249.
} 
al contrato individual de trabajo para tipificar las obligaciones a que debe sujetarse el trabajador, cuya transgresión si es grave habilita para aplicar el despido disciplinario. Pero no es la única norma que permite a la convención laboral establecer las obligaciones y prohibiciones laborales, también lo son los artículos $6^{\circ}$ y $7^{\circ}$ del Código del Trabajo, al definir el contrato individual de trabajo, y el artículo 10 del mismo Código, que establece el contenido mínimo del mismo, destacando su número 7, que permite "los demás pactos que acordaren las partes". Por su parte, el artículo 160 № 2 del Código del Trabajo permite estipular la prohibición de competencia, al establecer como causa del despido disciplinario las "Negociaciones que ejecute el trabajador dentro del giro del negocio y que hubieren sido prohibidas por escrito en el respectivo contrato por el empleador".

Respecto a la negociación colectiva, al tener por objeto establecer condiciones comunes de trabajo (artículo 303 del Código del Trabajo) que se pactarán en un instrumento colectivo de trabajo, sea un contrato colectivo, un convenio colectivo o fallo arbitral (artículos 60, 344 y 351 del Código del Trabajo), pueden comprenderse en los mismos las obligaciones y prohibiciones que deben observar los trabajadores en la empresa mientras ejecutan sus labores ${ }^{44}$. No existen dudas de esta posibilidad, debido a que las obligaciones y prohibiciones que deben cumplir los trabajadores mientras ejecutan sus labores constituyen condiciones comunes de trabajo, porque determinan la forma en que el dependiente debe ejecutar el trabajo convenido, moldeando su conducta en la empresa. No resulta vulnerado el artículo 306 inciso $2^{\circ}$ del Código del Trabajo ${ }^{45}$, porque el mismo, en nuestra opinión, solamente prohíbe que el ejercicio concreto de imponer sanciones no pueda ser compartido por el empleador con organizaciones sindicales o grupos de trabajadores, radicándose solamente en el empleador la posibilidad de imponer sanciones a sus dependientes, no pudiendo la misma ser objeto de la negociación colectiva, al formar parte de la facultad de organizar la empresa. Es el empleador el único que tiene la facultad para valorar una conducta reprochable, y decidir o no imponer una sanción como también materializar la misma, al ser el núcleo esencial del derecho potestativo en que

\footnotetext{
${ }^{44}$ La doctrina nacional señala refiriéndose a las condiciones comunes de trabajo: "este concepto es sumamente amplio y puede entenderse de acuerdo a lo planteado por el profesor uruguayo OsCAR ERMIDA como "conjunto de derechos, obligaciones, facultades, potestades y deberes propios de las relaciones individuales y aun colectiva". En este sentido: CaAmaño (2008), p. 130; CaAmaño y UGarte (2008), p. 53.

${ }^{45}$ Señala el artículo 306 inciso $2^{\circ}$ del Código del Trabajo: "No serán objeto de negociación colectiva aquellas materias que restrinjan o limiten la facultad del empleador de organizar, dirigir y administrar la empresa y aquellas ajenas a la misma". Véase sobre el sentido de esta norma: Dictamen de la Dirección del Trabajo No 5.603/88, de 25 de julio de 1989, que hace referencia a las facultades de administración en sentido amplio.
} 
se erige el ejercicio del poder disciplinario ${ }^{46}$, y no podría negarse o compartirse porque se negaría el derecho mismo ${ }^{47}$.

Debido a la complejidad de las relaciones laborales, que es cada vez más creciente, atendida la mayor sofisticación de la producción de bienes y servicios, es admisible que los cuerpos normativos antes señalados se remitan a otras reglamentaciones internas o externas a la empresa, que establecen obligaciones y prohibiciones. Lo que es legítimo, teniendo el mismo rango de validez que el cuerpo normativo que establece su remisión. Es así, que si el reglamento interno establece que los trabajadores deben observar las obligaciones y prohibiciones contenidas en procedimientos internos, código de conducta y otras normas internas de la empresa, la transgresión de estas obligaciones y prohibiciones habilita para castigar al infractor con las sanciones contempladas en el reglamento interno, desde que se vulnera el reglamento interno mismo, en la norma que se remite a otras normas, ordenando que sean observadas por los trabajadores. Asimismo, si es el contrato individual de trabajo el que establece una remisión en igual sentido, su transgresión da lugar a las mismas sanciones que proceden cuando se vulnera el contrato de trabajo mismo ${ }^{48}$. Como contrapartida, estas otras normas se sujetan a los mismos límites que los cuerpos normativos antes señalados.

Por otra parte, debe tenerse presente que aun cuando la conducta del trabajador vulnere obligaciones o prohibiciones previamente tipificadas, no será falta laboral si la conducta no es antijurídica, como ocurre si se actúa en defensa legítima propia o de otra persona ${ }^{49}$, al concurrir una eximente de responsabilidad

46 Rivero (1986), pp. 83-84; Fernández (1991), p. 42 nota 53; Gil (1993), p. 35.

47 Fernández (1991), p. 161.

${ }^{48}$ Se ha resuelto que la causal de incumplimiento grave prevista en el artículo $160 \mathrm{~N}^{\circ} 7$ del Código del Trabajo se configura tanto cuando se incumple el contrato de trabajo mismo como cuando se transgreden obligaciones y prohibiciones del reglamento interno cuando aquél se remite a éste. En este sentido: Corte de Apelaciones de Santiago, 10 de julio de 2003, GJ № 277 (2003), p. 268; Corte de Apelaciones de Santiago, 21 de septiembre de 2005, GJ № 303 (2005), pp. 246-247. En igual sentido la doctrina: Lanata (2010), p. 281; Gamonal y Guidi (2012), p. 284; Walker y Arellano (2014), p. 403.

${ }^{49}$ Corte de Apelaciones de Santiago, Rol Reforma Laboral № 1.524-2014, 5 de enero de 2015, que sostiene: "Cuarto: si se despide al trabajador por las causales de la letra c) del $\mathrm{N}^{\circ} 1$ y del $\mathrm{N}^{\circ} 7$ del artículo 160 del Código del Trabajo, fundadas ambas en que aquél golpeó a otro trabajador, menester es que ese actuar sea antijurídico, lo que no sucede en la especie pues ya se ha dicho que el tribunal de la instancia ha fijado como un hecho que la agresión del actor a otro operario de la empresa lo fue en defensa legítima suya y de otra empleada que estaba siendo atacada. Y no se trata de traer al derecho laboral instituciones del derecho penal, se trata simplemente que, al igual que en el derecho penal el actuar típico puede no ser delito si falta la antijuridicidad, como ocurre si se actúa en legítima defensa, en materia laboral no se configuran las causales esgrimidas si ha quedado asentado que el actor se limitó a defenderse de un ataque injusto, pues ello le quita el carácter antijurídico a su obrar, éste se conforma a Derecho, pues todo individuo tiene la prerrogativa de defenderse él y de defender a terceros frente a agresiones ilegítimas: ello sirve de eximente penal y de justificación de la conducta 
disciplinaria. No se trata de traer al Derecho Laboral instituciones del Derecho Penal, se trata simplemente que, al igual que en el Derecho Penal, el actuar típico puede no ser falta laboral si falta la antijuridicidad.

\subsection{Modo de tipificación de las conductas sancionables}

La función de garantía asignada al régimen de predeterminación de las conductas sancionables reside esencialmente en el grado de especificidad de las obligaciones y prohibiciones que deben observar los trabajadores. La tipicidad de las normas de conducta persigue evitar que el empleador pueda crear la falta laboral con posterioridad a la conducta del trabajador, además, de posibilitar el conocimiento en vía preventiva por parte del trabajador de las obligaciones y prohibiciones laborales como también las consecuencias de su infracción, pudiendo orientar su propia conducta en el contexto laboral ${ }^{50}$. Cumple así la tipicidad en materia de incumplimientos laborales una función de garantía, en el sentido que sólo pueden sancionarse los comportamientos que vulneran las obligaciones y prohibiciones establecidas aún de forma genérica en la ley, en el instrumento colectivo de trabajo, en el contrato individual de trabajo, en el reglamento interno o en el reglamento de higiene y seguridad en el trabajo ${ }^{51}$. De este modo, si la conducta del trabajador no vulnera algunas de las obligaciones o prohibiciones establecidas en los instrumentos señalados o éstos no califican un hecho como falta laboral, el empleador no podrá ejercer legítimamente el poder disciplinario, por ausencia de un requisito constitutivo ${ }^{52}$ : la predeterminación de la conducta sancionable.

Tal exigencia, también imperante en el derecho comparado, ha conducido a parte de la doctrina extranjera a sostener subsistente en materia disciplinaria empresarial el principio de tipicidad en los mismos términos que en materia penal, exigiendo en la determinación previa de las faltas laborales, de las obligaciones y prohibiciones laborales el respeto de un rígido criterio de taxatividad, excluyendo la utilización de normas analógicas y de fórmulas generales o amplias en la determinación de la conducta a observar ${ }^{53}$.

que el empleador entiende ilegítima y adecuada a las causales referidas". En el mismo sentido: Corte de Apelaciones de Santiago, Rol Reforma Laboral № 1.685-2014, 28 de enero de 2015.

50 Mainardi (2002), p. 254; Di PaOla (2010), p. 84.

51 El profesor Gil señala: "La descripción de los hechos sancionables en el ámbito laboral cumple cabalmente la segunda de las funciones que se asignan a los tipos penales, a saber: la de garantía, en el sentido de que sólo podrán sancionarse los comportamientos que se hallen descritos, aún en forma genérica, en la ley o en el convenio colectivo o norma sectorial", Gil (1993), p. 38.

52 GIL (1993), p. 38.

${ }^{53}$ En este sentido: CASTRO (1993), pp. 62-63. Para lo sostenido por un sector de la doctrina italiana al respecto véase: Mainardi (2002), pp. 254-256; Di PaOla (2010), pp. 84-86; LaZZARI (2012), pp. 47-50. 
Sin embargo, resulta acertado sostener que no es exigible una integral transposición del principio penal de la tipicidad de los ilícitos al ámbito de poder disciplinario empresarial, rigiendo el mismo con mayor elasticidad, en base al cual se excluye la taxatividad penal, debido a que la norma disciplinaria no crea el ilícito, sino que solamente determina la correlación entre la sanción y la falta ${ }^{54}$. La exigencia de la precisa y preliminar individualización de cada falta o comportamiento calificable como infracción disciplinaria puede entenderse satisfecha mediante la determinación de categorías de faltas sancionables ${ }^{55}$, es decir, basta con que el comportamiento que deba observar el dependiente se encuentre determinando en sus elementos esenciales y que exista una correlación entre la falta laboral y la sanción correspondiente. Debe, eso sí, precisarse que es necesario que las normas de conducta sean debidamente enunciadas en forma adecuada, que permitan un preventivo y puntual conocimiento por parte del trabajador de las mismas, en la medida de lo posible ${ }^{56}$.

La predeterminación de las conductas sancionables debe ser flexible, desde que las mismas vienen contempladas en los cuerpos normativos pertinentes en función meramente cognoscitiva y no constitutiva del incumplimiento laboral ${ }^{57}$. Afirmación que, además, de lo señalado encuentra sustento en dos argumentos. Es así, que se sostiene que el poder disciplinario, por su propia naturaleza, requiere de flexibilidad. Esto porque si el empleador tiene la facultad de dirección, correspondiéndole en virtud de la misma la organización productiva

\footnotetext{
54 Spagnuolo y Ferraro (1975), p. 159. Se sostiene que "la falta laboral [...] no es producto de la tipificación previa [...] las garantías para el trabajador han de buscarse en el control de lo que el empresario ha estimado como falta laboral y de la adecuación de las medidas punitivas empresariales a la conducta del trabajador y a la finalidad [...] empresarial", CREMADEs (1969), p. 172. El profesor Gil señala: "la descripción de los comportamientos laborales ilícitos cumple una función de garantía y, aun cuando no tiene por qué ser en extremo precisa y minuciosa, tampoco puede ser tan vaga y difusa que atribuya al empresario una facultad incondicionada para ejercer el poder disciplinario", GIL (1993), p. 40. Por su parte los profesores OlEa y CASAS señalan: "el poder disciplinario no está en lo laboral sujeto en la misma medida que el penal o público de sanción a la regla estricta nullum crimen sine lege y no exige, por tanto, tipificación precisa y cerrada de los actos y conductas sancionables, aunque sí desde luego la presencia de éstos", Olea y CASAS (2006), p. 442.

55 Spagnuolo y Ferraro (1975), p. 159.

${ }^{56}$ Existen diversos argumentos por los cuales no es trasladable íntegramente el principio de tipicidad penal (nullum crimen sine lege) al régimen disciplinario empresarial. El derecho penal protege intereses relevantes de la sociedad, mientras que el poder disciplinario opera al interior del contrato individual de trabajo, siendo funcional a la tutela de intereses no generales sino particulares del empleador, vinculados a su poder de dirección. Por otro lado, la tipicidad de la norma penal deriva de la función de cualificar un determinado acto como delito, creando el ilícito penal, en cambio en el ámbito disciplinario las normas se limitan a calificar ciertas conductas como faltas laborales, más no las crean. Véase sobre estos argumentos: MAINARDI (2002), pp. 229-230; LAZZARI (2012), pp. 47-50. En similares términos: Gil (1993), pp. 37-38.

57 Mainardi (2002), p. 257.
} 
de la actividad empresarial, no puede privársele de la posibilidad de valorar cuándo una conducta atenta contra el orden en la organización ${ }^{58}$, la que debe calificarse con cierta elasticidad y, a eso conduce, precisamente, la tipificación interna de las conductas sancionables. De exigirse una tipificación rígida de las obligaciones y prohibiciones laborales se corre el riesgo que el poder disciplinario quede privado de su vitalidad ${ }^{59}$.

También,se fundamenta la flexibilidad de la tipificación de las conductas laborales que pueden ser sancionadas, en las peculiaridades del trabajo que realizan los trabajadores en la empresa. Éstas vuelven imposible predecir todas las conductas que pueden producirse con el resultado de alterar el orden en la empresa y la convivencia entre los trabajadores ${ }^{60}$. Es por ello que de exigirse por el ordenamiento laboral un riguroso listado de faltas importaría congelar el estado de cosas en un determinado momento sin posibilidad de poder considerar las conductas ilícitas que pueden tener lugar en el futuro y que no han sido tipificadas previamente en alguno de los instrumentos idóneos para ello, y que pueden aconsejar su sanción ${ }^{61}$.

En consecuencia, el principio de legalidad en su vertiente tipicidad no significa que deba existir una tipificación rígida y taxativa de las infracciones laborales que limite por completo al empresario su facultad de valorar las conductas e incumplimientos de los trabajadores, lo que sería contrario al correcto desarrollo de la actividad empresarial, que conlleva una dinamicidad y agilidad necesaria para el mantenimiento de la misma en la actual economía llena de competitividad y adaptaciones a los cambios ${ }^{62}$. De ahí, que sea necesario tener en cuenta la multitud de acontecimientos y conductas que pueden concurrir en el caso concreto, y la posibilidad de valorarlas por el empleador, dotándolo de la posibilidad de sancionarlas legítimamente o no.

58 FERNÁNDEZ (1991), p. 155.

59 Megnoni (1985), p. 404.

60 Fernández (1991), p. 155; Papaleoni (1996), pp. 169-170; Mainardi (2002), p. 257; Di Paola (2010), p. 85; LAZZARI (2012), pp. 48-49. Se ha resuelto: "60) [...] el legislador laboral ha supuesto que el contrato contiene pactos tácitos que se relacionan con la educación, el decoro y las buenas relaciones que deben mantenerse entre quienes laboran en un mismo lugar. Ciertamente algunas empresas lo manifiestan en los reglamentos internos de orden, higiene y seguridad, pero esta materialización es también ejemplar, toda vez que entender que el contrato, anexos o reglamento interno contienen un catálogo taxativo de las obligaciones que se le imponen al trabajador, llevaría al absurdo de tener que plasmar obligaciones tales como saludar al llegar a la oficina, no maltratar a los subordinados, no tocar inapropiadamente a las trabajadoras, etc., lo que claramente atenta contra la más básica inteligencia" (Corte de Apelaciones de Santiago, Rol Reforma Laboral № 1.244-2014, 16 de enero de 2015).

61 Zangari (1971), p. 22; D’Avossa (1989), pp. 38-39; MaINARDI (2002), p. 257.

62 Poquet (2011), p. 47. 
Por otro lado, debe tenerse presente que ciertos deberes y obligaciones que deben cumplir las partes forman parte de la naturaleza de la relación laboral, no siendo necesario que se precisen por escrito previamente a su infracción, tal como ocurre con los deberes de actuar de buena fe y honesti$\mathrm{dad}^{63}$, de mantener buen trato con los compañeros de trabajo y superiores ${ }^{64}$ $y$, en general, con los deberes que forman parte del contenido ético-jurídico del contrato de trabajo, puesto que constituyen atributos de la conducta que deben regir el actuar de todo contratante en el cumplimiento de sus obligaciones y prohibiciones sin necesidad de tipificación previa ${ }^{65}$. El artículo 1546

${ }_{63}$ Corte Suprema, 31 de julio de 1990, GJ № 122 (1990), p. 90, que sostiene "3‥ [...] se deben entender incorporadas a aquél las normas de honradez inherentes a toda actividad humana, aun cuando no exista texto expreso que así lo imponga, dado que la honradez no puede quedar sujeta a la existencia o no de una disposición expresa que la establezca"; Corte de Apelaciones de Santiago, Rol Reforma Laboral NN 1118-2010, 17 de diciembre de 2010, sostiene: "5o) [...] la honradez es un atributo insoslayable en la conducta de todas las partes de un contrato, contrato que, para llegar a simbolizar "la ley" a que hace referencia el artículo 1545 del Código Civil, ha de tener no solo en su génesis sino también en sus actos preparatorios todos los pormenores de la buena fe, a la que debe rendirse culto durante todo el desarrollo de la relación contractual [...]. Como tal, la buena fe y la honestidad no necesitan texto expreso en ninguna relación contractual, puesto que constituyen atributos de la conducta de la persona que deben por sí solos embellecer el actuar de todo contratante en todos los ámbitos en que dentro del vínculo laboral se desempeñe".

${ }^{64}$ Corte de Apelaciones de Santiago, Rol Reforma Laboral № 1.244-2014, 16 de enero de 2015, que concluye: $6^{\circ}$ ) Que, como se ha sostenido por nuestros tribunales, el contrato de trabajo se encuentra también marcado por un contenido ético, es decir, por el imperio de ciertos principios que las partes deben respetar, entre ellos, el deber de respeto y buen trato a que ambas se encuentran obligadas, deber que además se extiende a las personas que conforman el grupo humano que erige la empresa, se trata de un contenido implícito, vinculado a los valores que deben regir las relaciones humanas, así las cosas, no es necesario que un contrato contenga la obligación de tratar con respeto a los jefes superiores y a los trabajadores subordinados, para entender que la obligación está contenida en el pacto laboral".

${ }^{65}$ Corte Suprema, Rol No 821-2012, 18 de octubre de 2012. Sentencia recaída en recurso de unificación de jurisprudencia, que sostiene: Tercero: Que si bien es cierto en el contrato de trabajo de la actora nada se dice respecto de la forma de uso del beneficio de los pasajes liberados, como lo ha declarado esta Corte en otras oportunidades, la señalada convención se caracteriza también por su contenido ético, es decir, por el imperio de ciertos principios que las partes deben respetar, entre ellos, el deber de fidelidad y lealtad a que ambas se encuentran obligadas. Por lo mismo, las relaciones laborales han de desenvolverse en un clima de confianza, el que se genera en la medida que las partes cumplan con sus obligaciones en la forma estipulada, de buena fe, principio del cual se encuentra imbuida toda la legislación nacional y consagrado, especialmente en materia contractual, en el artículo 1546 del Código Civil. De esta manera, los mencionados deberes constitutivos de la carga ética aludida, son claras directrices del comportamiento de los contratantes durante la vigencia de su vinculación, sujetándolos a varias obligaciones que, con independencia de su explicitación en el texto del contrato pertinente o consensuados expresamente, emanan de la naturaleza de la relación laboral y deben considerarse integrantes del mismo". En similares términos: Corte Suprema, Rol № 2512-2011, 2 de enero de 2012; Corte Suprema, Rol № 1162-2012; 3 de enero de 2013. 
del Código Civil, aplicable al contrato de trabajo en virtud de la aplicación supletoria del Código Civil, deja en claro que no sólo existen obligaciones expresas, sino también que emanan de la naturaleza del contrato, de la ley o la costumbre ${ }^{66}$, confirmando la tipicidad atenuada de las obligaciones y prohibiciones laborales.

La única excepción a la tipicidad atenuada de las faltas laborales la constituye, al parecer, la prohibición de competencia desleal durante el contrato de trabajo prevista en el artículo $160 \mathrm{~N}^{\circ} 2$ del Código del Trabajo, que exige entre sus requisitos, que conste por escrito en el respectivo contrato por el empleador $^{67}$. Sin embargo, no es una opinión unánime, puesto que existe un sector de la doctrina que sostiene que la regla general es la prohibición de competencia, la que sólo se puede alterar en caso de autorización del empleador ${ }^{68}$, no exigiendo, por tanto, una escrituración previa.

Al regir una tipicidad atenuada, se configura la falta laboral no sólo cuando se vulneran obligaciones y prohibiciones previamente escritas, sino también cuando se infringen deberes y prohibiciones implícitos emanados de la buena fe contractual, de la costumbre o de la naturaleza del contrato. Incluso, cuando se transgreden las órdenes e instrucciones verbales impartidas por el empleador en el contexto de la relación de trabajo.

\section{4. Área del incumplimiento laboral y conductas extrañas al contrato de trabajo}

Con la plena certeza que tutela la posición jurídica del empleador -primaria y secundaria o accesoria- en el contrato de trabajo, la delimitación del campo de actuación del ejercicio del poder disciplinario se circunscribe al ámbito del incumplimiento de una obligación o prohibición laboral, sea de fuente legal, contractual o reglamentaria en sentido estricto, por parte del trabajador. Fuentes que regulan, indistintamente, los deberes de prestación y de conducta ${ }^{69}$ que debe

${ }^{66}$ Corte de Apelaciones de San Miguel, Rol Reforma Laboral № 428-2014, 13 de enero de 2015.

67 Gaete (1967), p. 243; Walker y Arellano (2014), p. 461. En igual sentido un sector de la jurisprudencia: Corte Suprema, 8 de septiembre de 1981, RDJ, T LXXVIII, 2ª parte, sección 3a (1981), p. 97; Corte de Apelaciones de Santiago, 12 de junio de 1986, GJ № 72,1986, p. 95; Corte Suprema, 28 de mayo de 2002, GJ № 263 (2002), p. 189, que sostiene: "Primero: Que para que el empleador pueda invocar la causal consignada en el artículo $160 \mathrm{~N}^{\circ} 2$ del Código del Trabajo, se requiere la existencia de dos requisitos, que deben darse en forma copulativa, cuales son: a) que el trabajador realice negociaciones dentro del giro del negocio; y b) que estas negociaciones hubieren sido prohibidas en el respectivo contrato de trabajo en forma específica"; Corte de Apelaciones de Puerto Montt, Rol Reforma Laboral № 130-2014, 14 de octubre de 2014.

${ }^{68}$ Thayer y Novoa (2010), p. 53; IRUReta (2012 a), p. 81.

${ }^{69}$ Se diferencian en la ejecución del contrato de trabajo los "deberes de prestación" y los "deberes de conducta". Se señala que "los primeros tienen una especial connotación económica, y se traducen 
observar el trabajador en la prestación de trabajo y con ocasión de la misma, complementándose mutuamente.

La división que realiza la doctrina entre conducta del trabajador que se traduce sobre el plano disciplinario en: incumplimiento de la obligación de prestación, conducta que afecta la organización de la empresa y conducta que atenta contra la obligación de observar la disciplina del trabajo impartida por el empleador o sus colaboradores, tiene utilidad para analizar la amplia gama de comportamientos sancionables tenidos por el trabajador dependiente ${ }^{70}$. Esta distinción no tiene relevancia para los efectos de determinar el tipo de sanción que puede imponer el empleador, debido a que tanto la transgresión de los deberes de prestación como los deberes de conducta permiten imponer cualquiera de las sanciones, sean conservativas o extintivas de la relación laboral, en la medida que cumplan los requisitos del incumplimiento laboral sancionable y la gravedad necesaria.

Tanto en los reglamentos internos como en los contratos individuales de trabajo es posible encontrar una multiplicidad de disposiciones que contemplan, deberes, obligaciones y prohibiciones, muchos de las cuales son similares entre dependientes de la misma empresa como entre diversas empresas, especialmente las contenidas en el reglamento interno y en el reglamento de higiene y seguridad en el trabajo, sin perjuicio que existan disposiciones diversas. Esto último se debe principalmente a la heterogeneidad de actividades que desarrollan las empresas, los valores que representan, lo que conduce a establecer normas internas diversas entre ellas por esas circunstancias, destinadas a proteger los intereses particulares de cada empleador.

Teniendo presente la debida relación entre el contrato individual de trabajo, el reglamento interno y el Código del Trabajo, constituye falta laboral la conducta del dependiente que configura un incumplimiento de la prestación de trabajo en relación a la modalidad de ejecución con violación de la obligación de diligencia, que deriva de la naturaleza de la prestación debida. Constituyen infracciones de este primer tipo, a título ejemplificativo, según la mayoría de las fuentes de naturaleza convencional, reglamentaria interna y legal: la ausencia

en el cumplimiento de prestaciones recíprocas y típicas del contrato de trabajo (el trabajador aporta su fuerza laboral y el empleador paga una remuneración por ello). Los segundos vienen a calificar o descalificar el íntegro cumplimiento de los primeros; presentan un carácter eminentemente ético y dicen relación con el cumplimiento de las obligaciones contraídas dentro del marco de buena fe lo cual, por lo demás, está expresamente reconocido en el artículo 1546 del Código Civil, según cuyo mandato los contratos deben ejecutarse de buena fe", LANATA (2010), p. 282. En igual sentido: Corte de Apelaciones de Concepción, 13 de octubre de 2000, RDJ, T. XCVII, 2 $2^{\mathrm{a}}$ parte, sección 3ª (2000), p. 183.

70 Mainardi (2002), pp. 120 ss. 
injustificada al trabajo ${ }^{71}$, el abandono injustificado del trabajo ${ }^{72}$, el retardo en el inicio de la ejecución del trabajo diario ${ }^{73}$, la suspensión no autorizada o término anticipado de la prestación de trabajo, la negativa o el retardo en el traslado dispuesto por el empleador, el comportamiento incorrecto respecto a los clientes del empleador ${ }^{74}$, el deficiente rendimiento, la ejecución lenta o negligente de la prestación laboral ${ }^{75}$, la negligencia en el cuidado del local a su cargo o de los materiales de trabajo puestos a su cuidado ${ }^{76}$, la no ejecución del

${ }^{71}$ En el Código del Trabajo se contempla como causal de extinción del contrato de trabajo en el artículo 160, al disponer: "3. No concurrencia del trabajador a sus labores sin causa justificada durante dos días seguidos, dos lunes en el mes o un total de tres días durante igual período de tiempo; asimismo, la falta injustificada, o sin aviso previo de parte del trabajador que tuviere a su cargo una actividad, faena o máquina cuyo abandono o paralización signifique una perturbación grave en la marcha de la obra". Véase un análisis de esta causal de despido: IRURETA (2013 c), pp. 39-65. Se ha discutido en la jurisprudencia judicial si las inasistencias injustificadas al trabajo que no se subsumen en la causal del artículo $160 \mathrm{~N}^{\circ} 3$ pueden dar lugar a la configuración de la causal de despido del № 7 del mismo artículo, habiéndose pronunciado la Corte Suprema en recurso de unificación de jurisprudencia en sentido afirmativo, esto es, que puede encuadrarse dicha conducta en la causal de incumplimiento grave de las obligaciones que impone el contrato (Corte Suprema, Rol № 1242-2013, 13 de junio de 2013).

${ }^{72}$ Se establece como causal de despido disciplinario en el artículo $160 \mathrm{~N}^{\circ} 4$ del Código del Trabajo el: "Abandono del trabajo por parte del trabajador, entendiéndose por tal: a) la salida intempestiva e injustificada del trabajador del sitio de la faena y durante las horas de trabajo, sin permiso del empleador o de quien lo represente, $y$ b) la negativa a trabajar sin causa justificada en las faenas convenidas en el contrato".

${ }^{73}$ Los atrasos reiterados pueden configurar la causal de despido del artículo 160 № 7 del Código del Trabajo, siendo justificado el despido. Véanse: Corte Suprema, Rol № 883-2010, 28 de abril de 2010; Corte Suprema, Rol No 3729-2010, 19 de agosto de 2010; Corte Suprema, Rol № 4125-2010, 20 de octubre de 2010; Corte Suprema, Rol No 1575-2011, 24 de diciembre de 2011; Corte de Apelaciones de Valparaíso, Rol Reforma Laboral № 339-2012, 19 de noviembre de 2012; Primer Juzgado de Letras del Trabajo de Santiago, RIT O-84-2013, 16 de abril de 2013; Corte Suprema, Rol № 1242-2013, 13 de junio de 2013; Corte de Apelaciones de Santiago, Rol Reforma Laboral № 175-2014, 1 de agosto de 2014.

${ }^{74}$ Se comprenden entre estas conductas: falsificación de firma del cliente en documentos a presentar al empleador necesarios para obtener un producto crediticio (Juzgado de Letras del Trabajo de Antofagasta, RIT 0-815-2012, 17 de enero de 2014; Corte de Apelaciones de Valparaíso, Rol Reforma Laboral $N^{\circ} 375-2014,2$ de octubre de 2014), agresiones físicas a clientes (Corte de Apelaciones de Santiago, Rol Reforma Laboral № 503-2014, 21 de agosto de 2014), trato vejatorio a la intimidad del cliente mediante Ilamados telefónicos para cobrar el crédito adeudado al empleador (Corte de Apelaciones de Santiago, Rol Reforma Laboral № 1765-2012, 22 de marzo de 2013); agresiones verbales y físicas de clientes (Corte de Apelaciones de Valparaíso, Rol Reforma Laboral № 368-2013, 27 de noviembre de 2013).

75 Véase: Segundo Juzgado de Letras del Trabajo de Santiago, RIT O-1579-2012, 16 de agosto de 2012; Juzgado de Letras del Trabajo de Chillán, RIT O-254-2013, 29 de abril de 2014; Segundo Juzgado de Letras del Trabajo de Santiago, RIT O-4027-2013, 25 de febrero de 2014; Corte de Apelaciones de San Miguel, Rol Reforma Laboral № 144-2014, 13 de junio de 2014; Corte de Apelaciones de Valparaíso, Rol Reforma Laboral № 440-2014, 25 de noviembre de 2014.

${ }^{76}$ Véase: Corte de Apelaciones de Santiago, Rol Reforma Laboral № 875-2014, 25 de noviembre de 2014. 
trabajo extraordinario legítimamente solicitado por el empleador o convenido por las partes.

Constituyen, igualmente, faltas laborales las conductas del trabajador que atentan contra las normas e instrucciones impartidas por el empleador que tutelan el regular desenvolvimiento del trabajo, pudiéndose mencionar a modo de ejemplo: la inobservancia de las disposiciones de servicio o de ejecución de la prestación laboral, el comportamiento denigratorio en contra del empleador, la inobservancia de la forma de informar y justificar la enfermedad que le impide ejecutar la prestación debida, la inobservancia de las normas en materia de seguridad en la empresa o de seguridad en el trabajo ${ }^{77}$, llegar al trabajo en estado de intemperancia alcohólica ${ }^{78}$ o bajo la influencia de drogas ${ }^{79}$, el consumo de alimentos ${ }^{80}$, de bebidas alcohólicas o de drogas ${ }^{81}$ durante la jornada de trabajo, dormir en el lugar de trabajo ${ }^{82}$, la falsificación de documentos en el lugar de

\begin{abstract}
77 Existe una causal de despido disciplinario que sanciona estas faltas laborales, la del artículo 160 № 5 del Código del Trabajo, que dispone: "Actos, omisiones o imprudencias temerarias que afecten a la seguridad o al funcionamiento del establecimiento, a la seguridad o a la actividad de los trabajadores, o a la salud de éstos". La sentencia de la Corte Suprema, de 23 de mayo de 2013, Rol No 292-2013, pronunciada en recurso de unificación de jurisprudencia, determinando el sentido de esta causal de despido, concluye: "Sexto: Que esta causal, contemplada en el No 5 del artículo 160 del Código del Trabajo, supone en primer término que los hechos ejecutados por el dependiente sean extremadamente imprudentes o con una negligencia considerable. No se requiere entonces una intencionalidad especial, sino un olvido inexcusable de las precauciones que la prudencia común aconseja y que conduce a la realización de hechos que, de mediar malicia, constituirían delito. Deberán, además, afectar a los bienes jurídicos establecidos en la norma referida, expresión que no puede entenderse como sinónimo de producción cierta de un daño, sino sólo como la posibilidad concreta de que ese perjuicio se produzca, atendido que en el caso en que lo amenazado sea la salud de otros dependientes la disposición del artículo 184 del Código del ramo prevé la obligación esencial del empleador de adoptar todas las medidas necesarias para proteger eficazmente la vida y salud de los dependientes". Véanse: Corte Suprema, 23 de abril de 1993, RDJ, T. XC, $2^{\text {a }}$ parte, sección $3^{\text {a }}$ (1993), pp. 28-29; Corte de Apelaciones de la Serena, 24 de julio de 2002, RFM No 517 (2002), p. 3606; Corte Suprema, 28 de abril de 2005, GJ № 298 (2005), pp. 254-255; Corte de Apelaciones de Talca, Rol Reforma Laboral № 100-2014, 29 de julio de 2014; Corte de Apelaciones de Concepción, Rol Reforma Laboral № 326-2014, 17 de diciembre de 2014.
\end{abstract}

${ }^{78}$ Corte de Apelaciones de Santiago, 26 de abril de 1988, GJ № 102 (1988), pp. 78-79; Corte de Apelaciones de Santiago, 5 de septiembre de 1989, GJ № 111 (1989), p. 105; Corte Suprema, 14 de octubre de 2002, GJ No 268 (2002), p. 180; Corte Suprema, Rol № 2230-2011, 2 de diciembre de 2011; Corte de Apelaciones de Puerto Montt, Rol Reforma Laboral № 179 - 2014, 27 de enero de 2015.

${ }^{79}$ Corte de Apelaciones de Santiago, 21 de septiembre de 2005, GJ No 303 (2005), pp. 246-247; Corte de Apelaciones de Santiago, Rol Reforma Laboral № 23-2014, 16 de abril de 2014.

80 Sentencia de la Corte de Apelaciones de Santiago, 11 de mayo de 2012, Rol Reforma Laboral No 1616-2011, identificador microjuris MJJ31937.

${ }^{81}$ Corte de Apelaciones de Antofagasta, Rol Reforma Laboral № 30-2014, 20 de junio de 2014.

82 Corte Suprema, 28 de mayo de 1986, GJ № 71 (1986), pp. 69-70; Corte de Apelaciones de Santiago, 5 de septiembre de 1989, GJ № 111 (1989), p. 105; Corte de Apelaciones de Santiago, 3 de noviembre de 1998, GJ No 221 (1998), p. 206. 
trabajo ${ }^{83}$, la alteración del sistema de control dispuesto por el empleador para la presencia en el trabajo y cumplimiento de jornada de trabajo ${ }^{84}$, la transgresión de la prohibición de fumar en el lugar de trabajo, la no comunicación del cambio de domicilio, la instigación a otros trabajadores para cometer conductas de insubordinación.

También entran en la categoría de conductas que afectan el regular y ordinario funcionamiento de la organización empresarial aquellas conductas que, por el carácter violento, litigioso o injurioso, pueden alterar la tranquilidad del ambiente laboral y la relación interpersonal entre el empleador y el trabajador infractor, pudiendo ser la falta laboral, incluso, relevante para efectos penales, si configura también un ilícito penal. Pertenecen a esta categoría de infracciones laborales: la riña o altercado pendenciero con colegas de trabajo ${ }^{85}$, discusiones con compañeros de trabajo ${ }^{86}$, lesiones a su superior jerárquico ${ }^{87}$ o compañero de trabajo ${ }^{88}$, injurias a su empleador ${ }^{89}$, comportamientos de carácter sexual ${ }^{90} \mathrm{O}$ que configuran un acoso laboral ${ }^{91}$. Todas faltas laborales lesivas de la dignidad de la persona.

83 Sentencia del Juzgado de Letras del Trabajo Antofagasta, 17 de enero de 2014, RIT O-815-2012.

${ }^{84}$ Corte Suprema, 6 de julio de 1988, GJ № 97 (1988), p. 81; Corte de Apelaciones de Santiago, Rol Reforma Laboral № 587-2014, 26 de junio de 2014.

85 Véase IRURETA (2013 b), pp. 179-206.

${ }^{86}$ Corte de Apelaciones de Santiago, 8 de enero de 1988, RDJ, T. LXXXV, $2^{\text {a }}$ parte, sección $3^{\text {a }}$ (1988), p. 35; Corte de Apelaciones Pedro Aguirre Cerda, 29 de abril de 1985, GJ No 58 (1985), p. 174; Corte Suprema, 9 de marzo de 1999, RFM No 484 (1999), pp. 216-217; Corte de Apelaciones de Santiago, Rol № 667202009, 12 de mayo de 2010.

${ }^{87}$ Se contempla como causal de despido disciplinario: "Alguna de las conductas indebidas de carácter grave, debidamente comprobadas, que a continuación se señalan: 1. [...] c) Vías de hecho ejercidas por el trabajador en contra del empleador o de cualquier trabajador" (artículo 160 № 1 del Código del Trabajo).

${ }^{88}$ Corte de Apelaciones de Santiago, 1 de julio de 1998, GJ No 217 (1998), p. 205; Corte Suprema, 6 de noviembre de 2002, RFM No 504 (2002), p. 3948.

${ }^{89}$ Se establece en el artículo 160 del Código del Trabajo como causal de despido: "Alguna de las conductas indebidas de carácter grave, debidamente comprobadas, que a continuación se señalan: 1. [...] d) Injurias proferidas por el trabajador al empleador". Véase: Corte Suprema, 8 de septiembre de 2004, GJ No 291 (2004), pp. 205-206.

${ }^{90}$ El artículo 160 del Código del Trabajo señala como causal de despido: "Alguna de las conductas indebidas de carácter grave, debidamente comprobadas, que a continuación se señalan: 1. [...] b) conductas de acoso sexual". Véase sobre el acoso sexual en Chile: CaAmaño (2004), pp. 93-114; Lanata (2004), pp. 83-104; Lizama y Ugarte (2005); CaAmaño et al. (2005); Koch (2005), pp. 83-87; Palavecino (2006), pp. 105-123.

${ }^{91}$ El artículo 160 del Código del Trabajo tipifica como causal de despido: "Alguna de las conductas indebidas de carácter grave, debidamente comprobadas, que a continuación se señalan: 1. [...] f) Conductas de acoso laboral". Véase sobre la regulación del acoso laboral en Chile: Gamonal y Prado (2009); Palavecino (2012), pp. 13-28; CaAmaño (2013), pp. 65-77; CaAmaño y Ugarte (2014), pp. 67-90. 
Igualmente, no parece existir debate que forman parte de las infracciones relevantes sobre el plano disciplinario la violación de la obligación de buena fe. En este caso la violación puede ser fuente de responsabilidad disciplinaria y, a la vez, de responsabilidad civil, aunque esta última no se haga efectiva, no existiendo impedimento en su concurrencia conjunta en base a una misma conducta, por cuanto la primera no se dirige a reparar el daño eventualmente causado al empleador, mientras que la segunda puede ser activada aun en ausencia de sanción disciplinaria y hasta ejercerse antes de la extinción del contrato de trabajo ${ }^{92}$. La violación de la obligación de buena fe se manifiesta en comportamientos tales como: la ejecución en la empresa durante la jornada laboral de trabajo propio ${ }^{93}$ o de un tercero, apoderamiento de documentos de la empresa, la revelación de secretos o información reservada de la empresa, la ejecución de actividades económicas en competencia o en conflicto de intereses con el empleador ${ }^{94}$, la sustracción de especies de propiedad del empleador ${ }^{95}$ o que se encuentran bajo su custodia ${ }^{96}$, la falsificación de documentos del

92 Cremades (1969), p. 240; Castro (1993), pp. 211-2014; Mainardi (2002), p. 168; Di Paola (2010), p. 14; Mainardi (2012), pp. 89-90; Terradillos (2004), pp. 66-67; Poquet (2011), pp. 110-111. En igual sentido en la doctrina nacional: Macchiavello (1986), I, p. 253; Gamonal y Guidi (2012), p. 102; FerNÁNDEZ (2014), pp. 173-174.

${ }^{93}$ Corte Suprema, 13 de septiembre de 1999, RDJ, T. XCVI, $2^{a}$ parte, sección $3^{\text {a }}$ (1981), p. 200.

94 IRURETA (2011), pp. 177 ss. Véanse: Corte Suprema, 8 de septiembre de 1981, RDJ, T. LXXVIII, $2^{a}$ parte, sección $3^{a}$ (1981), p. 97; Corte Suprema, 1 de diciembre de 1983, RFM No 301 (1983), p. 792; Corte de Apelaciones de Santiago, 12 de junio de 1986, GJ № 72 (1986), p. 95; Corte Suprema, 28 de mayo de 2002, GJ № 263 (2002), p. 189; Corte Suprema, 15 de abril de 2003, RDJ, T. C, $2^{\text {a }}$ parte, sección $3^{a}$ (2003), pp. 50-51; Corte de Apelaciones de Santiago, Rol № 2147-2010, 3 de marzo de 2011; Corte de Apelaciones de Talca, Rol Reforma Laboral № 138-2014, 25 de agosto de 2014; Corte de Apelaciones de Puerto Montt, Rol Reforma Laboral No 130-2014, 14 de octubre de 2014.

95 Puede mencionarse: apropiación de dineros de propiedad del empleador (Corte de Apelaciones de Santiago, 26 de agosto de 1987, GJ № 86 (1987), pp. 86-87; Corte Suprema, 13 de mayo de 2003, GJ № 275 (2003), pp. 220-221; Corte de Apelaciones de Santiago, 5 de enero de 2004, GJ № 288 (2004), p. 267); apropiación de mercaderías del empleador (Corte de Apelaciones de Santiago, 2 de noviembre de 1987, GJ No 89 (1987), p. 85; Corte Suprema, 5 de agosto de 1999, RFM No 489 (1999), p. 1847; Corte de Apelaciones de Santiago, Rol Reforma Laboral № 981-2012, 9 de octubre de 2012; Corte de Apelaciones de Santiago, Rol Reforma Laboral № 1841-2012, 26 de agosto de 2013; Corte de Apelaciones de Puerto Montt, Rol Reforma Laboral № 113-2014, 15 de septiembre de 2014); apropiación de especies de propiedad del empleador (Corte de Apelaciones de Santiago, 25 de septiembre de 1990, RFM No 382 (1990), p. 551; Corte Suprema, 22 de abril de 1996, RDJ, T. XCIII, $2^{\text {a }}$ parte, sección $3^{\text {a }}$ (1981), pp. 44-45; Corte de Apelaciones de Concepción, 3 de diciembre de 2001, GJ № 261 (2002), p. 156; Corte Suprema, 23 de julio de 2002, RDJ, T. XCIX, $2^{a}$ parte, sección $3^{\text {a }}$ (2002), p. 169; Corte Suprema, Rol No 272-2010, 15 de abril de 2010, identificador LegalPublishing CL/JUR/17017/2010; Corte de Apelaciones de La Serena, Rol Reforma Laboral № 17-2014, 5 de mayo de 2014; Corte de Apelaciones de San Miguel, Rol Reforma Laboral № 229-2014, 27 de agosto de 2014).

${ }^{96}$ Cuando se extingue el contrato de trabajo por esta falta laboral se invocan las causales de los artículos $160 \mathrm{~N}^{\circ} 1$ letra a) y $7^{\circ}$ del Código del Trabajo, conjunta o separadas indistintamente, declarándose justificado el despido. Véase cuando se ha invocado la causal de falta de probidad del artículo $160 \mathrm{~N}^{\circ} 1$ 
empleador durante la ejecución del trabajo ${ }^{97}$, la entrega de información falsa para obtener beneficios patrimoniales de parte del empleador ${ }^{98}$, la utilización de herramientas de producción de la empresa para negocios personales ${ }^{99}$, la apropiación de dineros entregados por clientes ${ }^{100}$. Según se puede observar, en la jurisprudencia existe una presunción in re ipsa de máxima gravedad de tales conductas, que puede dar lugar a la sanción de máxima gravedad: el despido disciplinario.

Existe toda una serie de comportamientos de relevancia disciplinaria difícilmente catalogables dentro de las infracciones a los deberes de conducta o de prestación, siendo sustancialmente reconducibles a la generalísima obligación de buena fe en el contrato de trabajo, entrando en la órbita de esa obligación contractual, que tiene reconocimiento en el artículo 1546 del Código Civil e incidencia sobre el deber de fidelidad. Se trata siempre a título ejemplificativo: el fraude y daño al empleador, la percepción de compensación o regalías de parte de terceros para el desenvolvimiento normal del trabajo, el descrédito de la empresa frente a clientes o terceros, entre otros.

La enumeración de infracciones laborales derivada de la práctica contractual, de la normativa interna, de la ley y de la casuística jurisprudencial conserva un margen de exhaustividad de carácter relativo. Esto porque el poder disciplinario consciente todavía en circunscribir el área de incumplimientos relevantes para fines disciplinarios al ámbito de los comportamientos que afectan las obligaciones laborales y a aquellas disposiciones que resguardan en sentido amplio la relación de trabajo, con tendencia a excluir toda conducta que resguarda intereses externos a los del empleador u observada en la vida privada del trabajador sin conexión alguna con la relación laboral. Situación

letra a) del Código del Trabajo: Corte de Apelaciones de Santiago, Rol Reforma Laboral № 1926-2013, 5 de junio de 2014; Corte de Apelaciones de Santiago, Rol Reforma Laboral № 588-2014, 15 de septiembre de 2014; Corte de Apelaciones de Temuco, Rol Reforma Laboral № 86-2014; 11 de junio de 2014; Corte de Apelaciones de Puerto Montt, Rol Reforma Laboral № 113-2014, 15 de septiembre de 2014; Corte de Apelaciones de Antofagasta, Rol Reforma Laboral № 178-2014, 5 de diciembre de 2014. Véase cuando se ha invocado la causal de incumplimiento grave de las obligaciones que impone el contrato del artículo $160 \mathrm{~N}^{\circ} 7$ junto a la causal de falta de probidad: Corte de Apelaciones de Arica, Rol Reforma Laboral № 24-2014, 11 de julio de 2014. Véase cuando se ha invocado solamente la causal del artículo 160 № 7: Corte de Apelaciones de Concepción, Rol Reforma Laboral № 127-2013, 8 de julio de 2013; Corte de Apelaciones de San Miguel, Rol Reforma Laboral № 27 de agosto de 2014, Rol Reforma Laboral № 229-2014.

${ }_{97}$ Corte Suprema, 20 de junio de 2001, GJ № 252 (2001), p. 162.

${ }_{98}$ Corte de Apelaciones de Santiago, 11 de junio de 1987, GJ № 84 (1987), p. 95; Corte Suprema, 24 de enero de 1992, RFM No 398 (1992), pp. 891-892.

${ }_{99}$ Corte de Apelaciones de Santiago, 11 de enero de 1987, GJ No 91 (1987), pp. 74-75.

100 Corte de Apelaciones de Santiago, 29 de octubre de 2004, GJ № 292 (2004), pp. 256-257. 
que es defendida tanto por la doctrina nacional ${ }^{101}$ y extranjera ${ }^{102}$ como por la jurisprudencia judicial ${ }^{103}$ y administrativa ${ }^{104}$ nacional. Lo que resulta acertado, porque si en virtud del poder disciplinario se sancionan conductas que vulneran disposiciones legales, contractuales, del reglamento interno, del reglamento de higiene y seguridad en el trabajo u otras normas internas a que se remiten aquellos cuerpos normativos, los que solamente deben regular la conducta que debe observar el dependiente en la empresa durante la ejecución del trabajo como regla general, no pueden sancionarse las conductas extrañas al trabajo, que ninguna conexión tienen con el mismo. De este modo, si dichos cuerpos normativos contemplan disposiciones que determinan el comportamiento del dependiente más allá del trabajo convenido, que no protegen los intereses del empleador, no es legítima la sanción disciplinaria impuesta por transgresión de estas normas, al exceder las mismas el ámbito de competencia que le otorga el legislador al poder disciplinario. Se trata de normas de conducta que entran a regular la vida privada extralaboral del dependiente.

Sin embargo, el problema es complejo, invistiendo la temática de la relevancia de conductas extrañas a la relación laboral para fundar la extinción extraordinaria del contrato de trabajo por despido disciplinario o la aplicación de sanciones conservativas, una cuestión que requiere precisiones. La posición dominante es aquella que considera el comportamiento del todo extraño a la relación de trabajo como irrelevante para proceder a su extinción fundado en

\footnotetext{
101 FeRNÁNDEZ (2014), p. 5.

102 Fernández (1991), pp. 190-191; Mainardi (2002), p. 129; Di Paola (2010), pp. 68-70; RodríGuez (2008), p. 86; CRUZ (2010), p. 222; ConGeduti (2011), p. 9.

103 Se ha declarado injustificado el despido cuando se imputan al trabajador conductas que no dicen relación con el contrato de trabajo, sino con la vida privada del trabajador o extraña a la relación de trabajo. En este sentido: Corte de Apelaciones de Santiago, 17 de mayo de 1989, GJ № 107 (1989), pp. 88-89; Corte Suprema, 11 de junio de 1992, RFM No 403 (1992), p. 357; Corte de Apelaciones de Santiago, 15 de abril de 1997, GJ No 202 (1997), pp. 178-179.

104 Dictamen N ${ }^{\circ}$ 2.856/162 de la Dirección del Trabajo de 30 de agosto de 2002, el cual sostiene: "al empresario le es reconocido el ejercicio de una serie de facultades o prerrogativas que tienen por objeto el logro del referido proyecto empresarial en lo que al ámbito laboral se refiere, y que se traducen en la libertad para contratar trabajadores, ordenar las prestaciones laborales, adaptarse a las necesidades de mercado, controlar el cumplimiento y ejecución del trabajo convenido, y sancionar las faltas o los incumplimientos contractuales del trabajador. Estas facultades, que responden a lo que genéricamente se denomina poder de dirección-comprendiendo en este concepto amplio tanto el poder de dirección strictu sensu como el disciplinario-, si bien encuentran, como se dijo, sustento en la garantía constitucional de la libertad de empresa y el derecho de propiedad en cuanto conforman un cúmulo de facultades organizativas para el empresario, se definen y concretizan en cuanto a su extensión y configuración -ratio jurídica- en el contrato de trabajo -dichos poderes no pueden ejercerse más allá de la relación laboral y extenderse a la actividad extralaboral del trabajador-, a lo que debemos agregar la ley-será el legislador el que regule el ejercicio legítimo de este poder estableciendo normas mínimas irrenunciables, así como su uso no arbitrario".
} 
una causal del despido disciplinario o para imponer una sanción disciplinaria conservativa $^{105}$. De este modo, en la extinción del contrato individual de trabajo por faltas laborales debe considerarse la buena fe según un criterio objetivo de garantía de la confianza del empleador en el cumplimiento futuro del trabajo por el dependiente, pudiéndose considerar la lesión sólo en directa y específica correlación con el incumplimiento del trabajador, con su posición de trabajo en la empresa y la gravedad de la conducta ${ }^{106}$.

La confirmación de la irrelevancia para la configuración de la falta laboral de conductas extrañas a la relación contractual encuentra sustento en diversas disposiciones contenidas en la legislación laboral. Tratándose del reglamento interno, los artículos 153 y 154 Nº 9 del Código del Trabajo dejan en claro que solamente deben contemplarse en el mismo las obligaciones, prohibiciones y normas que deben observar los dependientes con ocasión de su permanencia en la empresa. Respecto al reglamento de higiene y seguridad, el artículo 67 de la Ley $\mathrm{N}^{0} 16.744$ señala que las disposiciones de seguridad en el trabajo que puede imponer el empleador a los trabajadores deben contenerse en dicho reglamento interno. El artículo $7^{\circ}$ del Código del Trabajo, al definir el contrato de trabajo, y el artículo 10 del mismo Código, que establece el contenido mínimo del contrato de trabajo, revelan que las obligaciones que deben contenerse en el mismo deben estar en directa conexión con las labores que se compromete a ejecutar el trabajador. Los artículos 60, 303, 344 y 345 del Código del Trabajo, al determinar el contenido de los instrumentos colectivos de trabajo, señalan que pueden regular las condiciones comunes de trabajo, siendo, por tanto, extraño a su objeto contener estipulaciones que no dicen relación con la conducta a observar en su calidad de trabajador dependiente quienes son parte del mismo.

La conducta extralaboral del trabajador es irrelevante para fines disciplinarios como regla general. Lo que el trabajador hace o deja de hacer fuera de su jornada de trabajo y lugar de trabajo, cuando no está a disposición del empleador no constituye objetivo de disciplina, del mismo modo, que no constituye un ámbito lícito de ejercicio del poder de dirección empresarial ${ }^{107}$. La necesaria naturaleza contractual laboral de la falta laboral impide que el poder disciplinario pueda ser ejercido por el empleador frente a las conductas extralaborales del trabajador. Regla general que es manifestación del valor superior de la libertad de la persona, que permite al trabajador determinar su conducta libremente en cualquier situación en que no resulta constreñido por las obligaciones laborales.

\footnotetext{
105 Mainardi (2002), pp. 129 ss.; Morato (2011), p. 107; Di Paola (2010), p. 69; Congeduti (2011), p. 9; BrÉGOU (2012), pp. 40, 48-50.

106 Mainardi (2002), pp. 129 ss.; Congeduti (2011), p. 9.

107 Montoya (1965), p. 193; Gómez (2009), p. 82; Mainardi (2002), p. 130; Di Paola (2010), p. 69; Congeduti (2011), p. 9; Pérez (2013), p. 56.
} 
La anterior no significa, como correctamente se ha observado, que eventuales situaciones extralaborales puedan ser utilizadas, en determinadas circunstancias, para extinguir el contrato individual de trabajo por despido disciplinario o, bien, para fundar la aplicación de una sanción laboral conservativa del contrato de trabajo, al constituir faltas laborales. Tales conductas, no por ser ejecutadas fuera de la jornada de trabajo, deben ser consideradas solo una accesión disciplinaria; su gravedad debe ser evaluada al igual que cualquier falta laboral, por el carácter ontológico de las mismas, siendo lo relevante que se encuentren comprendidas en el ámbito de comportamientos contractualmente relevantes ${ }^{108}$. Se trata de las obligaciones laborales que despliegan sus efectos cuando el trabajador deja de estar a disposición del empleador, constituyendo una manifestación de la buena fe contractual, concretizada en deberes de índole negativa o abstencionista, destacando: el deber de no competencia desleal ${ }^{109}$, el deber de no ofender al empleador u otras personas relacionadas con la empresa, el deber de no revelar secretos empresariales ${ }^{110}$, el deber de no trabajar para otro empleador durante el goce de licencia médica con reposo total ${ }^{111}$, el deber de no realizar fuera de la jornada de trabajo actividades que, por su naturaleza o efectos, lesionan bienes de la empresa'112, el deber de no sustraer o hurtar bienes de la empresa fuera de la jornada de trabajo ${ }^{113}$ o durante el goce de vacaciones ${ }^{114}$. De este modo, se observa que del contrato de trabajo derivan una serie de obligaciones,

108 Mainardi (2002), p. 130; Di PaOla (2010), p. 69; BrÉGou (2012), pp. 48-49.

${ }^{109}$ Corte Suprema, 8 de septiembre de 1981, RDJ, T. LXXVIII, $2^{a}$ parte, sección $3^{\text {a }}$ (1981), p. 97; Corte Suprema, 1 de diciembre de 1983, RFM No 301 (1983), p. 792; Corte de Apelaciones de Santiago, 12 de junio de 1986, GJ № 72 (1986), p. 95; Corte Suprema, 28 de mayo de 2002, GJ № 263 (2002), p. 189; Corte Suprema, 15 de abril de 2003, RDJ, T. C, $2^{\text {a }}$ parte, sección $3^{\mathrm{a}}$ (2003), pp. 50-51; Corte de Apelaciones de Santiago, Rol No 2147-2010, 3 de marzo de 2011; Corte de Apelaciones de Talca, Rol Reforma Laboral № 138-2014, 25 de agosto de 2014; Puerto Montt, Rol Reforma Laboral № 130-2014, 14 de octubre de 2014.

110 Gómez (2009), p. 82.

111 Se ha considerado falta de probidad trabajar para otra empresa durante el reposo total prescrito por una licencia médica. Véanse: Corte de Apelaciones de Valparaíso, Rol Reforma Laboral № 369-2012, 3 de diciembre de 2014; Corte de Apelaciones de Valparaíso, Rol Reforma Laboral № 488-2014, 30 de enero de 2015.

112 Corte de Apelaciones de Santiago, 12 de junio de 1995, RDJ, T. XCII, 2a parte, sección $3^{\text {a }}$ (1995), pp. 126-127 (desconexión y conexión de medidor fuera de la jornada de trabajo para hurtar energía eléctrica).

113 Se ha declarado justificado el despido fundado en la sustracción de mercaderías fuera de la jornada de trabajo, aprovechándose de la calidad de trabajador dependiente: Corte de Apelaciones de Concepción, Rol Reforma Laboral № 127-2013, 8 de julio de 2013.

114 Se ha declarado justificado el despido fundado en la sustracción de mercaderías durante el goce de vacaciones, aprovechándose de la calidad de trabajador dependiente: Corte de Apelaciones de Puerto Montt, Rol Reforma Laboral No 113-2014, 15 de septiembre de 2014. 
cuyo incumplimiento producido aun fuera del lugar de trabajo y ajena de la prestación del servicio configura una falta laboral ${ }^{115}$.

Es así, como comportamientos extralaborales excepcionalmente pueden constituir faltas laborales cuando lesionan intereses legítimos del empleador y la posición contractual del trabajador.

\subsection{Comportamientos extralaborales que configuran ilícitos penales y su influencia en la configuración de las faltas laborales}

Puede suceder que en la vida privada el trabajador incurra en una acción u omisión que lo hace merecedor de una medida cautelar personal o de una sanción penal, que es impuesta por los Tribunales de Justicia con competencia penal, no conectada al desenvolvimiento de la relación de trabajo, no afectando, por tanto, su ejecución, lo que ocurre con las medidas cautelares personales y penas no privativas de libertad. También, es posible que observe un comportamiento extralaboral que le hace merecedor de un castigo penal, que sí puede ser considerado para fines disciplinarios por su influencia sobre la prestación laboral.

En el primer caso rige el principio de la irrelevancia sobre el plano disciplinario de la conducta que constituye la comisión de determinado delito o que provoca la condena penal del trabajador, por no afectar la ejecución de la prestación laboral y las obligaciones que tiene el dependiente para con el empleador ${ }^{116}$. Se trata de una situación totalmente extraña a la relación de trabajo, no guardando ninguna conexión con la misma, por tanto, queda fuera del ámbito de acción del poder disciplinario. En el segundo supuesto, incluso, la predisposición del trabajador a delinquir debidamente demostrada, no puede constituir per se comportamiento de relevancia disciplinaria, especialmente, para proceder al despido disciplinario, siendo necesario al fin de imponer una sanción disciplinaria la demostración de la obligación específica del trabajador de no ejecutar un determinado hecho de relevancia penal o que afecta su posición en el trabajo, teniendo incidencia perjudicial sobre la esfera del empleador ${ }^{117}$. La prueba de tales circunstancias recae en el empleador, debiendo comprobar que el episodio delictuoso determinado influye negativamente sobre el ambiente de trabajo, que hace insostenible la prosecución de la relación de trabajo según el principio de proporcionalidad.

La conducta extralaboral del dependiente puede tener una particular gravedad en el ámbito laboral como indicio de un posible perjuicio para la

\footnotetext{
115 Pérez (2013), p. 57.

116 Fernández (1991), pp. 191 ss.; Mainardi (2002), p. 132; Congeduti (2011), p. 9.

117 FernáNDEZ (1991), pp. 191 ss.; MaINARDI (2002), p. 132.
} 
organización empresarial, gravando su expectativa y posibilidad de un correcto cumplimiento para el futuro de la prestación laboral, pudiendo configurar una falta laboral. Ahora bien, para proceder al despido disciplinario por conductas extrañas a la relación de trabajo siempre se requiere una necesaria correlación con el desenvolvimiento de la relación de trabajo, influyendo necesariamente tal conducta en el ambiente laboral y en la organización empresarial en forma negativa ${ }^{118}$. Lo que puede ocurrir en relaciones laborales, en que por sus características y peculiaridades, la prestación laboral exija un amplio margen de fidelidad y seriedad por parte del dependiente en su comportamiento en la vida privada.

Particular relevancia han adquirido en nuestro ordenamiento jurídico las consecuencias jurídicas que derivan de la imposición al trabajador de medidas cautelares personales privativas de libertad ${ }^{119}$, fundadas en conductas extrañas a la relación laboral, que le impiden concurrir a cumplir su jornada de trabajo. Esto porque se discute en la jurisprudencia judicial si las ausencias al trabajo derivadas de una medida cautelar personal impuesta por el órgano competente están o no justificadas, controversia generada especialmente a propósito de la impugnación del despido disciplinario fundado en la causal del artículo 160 $\mathrm{N}^{0} 3$ del Código del Trabajo ${ }^{120}$. Existen tres tendencias jurisprudenciales.

Un sector de la jurisprudencia ${ }^{121}$ sostiene que corresponde aplicar el derecho constitucional y legal de presunción de inocencia al trabajador que se encuentra privado de libertad producto de una medida cautelar personal, no pudiéndose aplicar un causal de término de la relación laboral fundada en las inasistencias a sus labores, por no serle imputable al trabajador dichas inasistencias, atendida la naturaleza de la resolución judical que ordenó su privación de libertad, esencialmente transitoria, modificable y revocable, no siendo atribuibles a la voluntad del trabajador los efectos que ésta traiga, y que son imposibles de resistir por éste, más aún cuando se entiende inocente hasta que no exista condena a través de una sentencia penal firme y ejecutoriada. De este modo, la privación de libertad decretada en virtud de una resolución judicial distinta a una sentencia definitiva condenatoria produce la suspensión del contrato individual de

\footnotetext{
118 Dı PAOLA (2010), p. 68.

119 Particularmente en el actual proceso penal la detención y la prisión preventiva, y en el anterior procedimiento penal el arresto.

120 Véase IRURETA (2013 c), pp. 53 ss.

121 Corte Suprema, 6 de abril de 1999, RFM No 485, 1999, p. 555; Corte de Apelaciones de Santiago, Rol No 9973-2009, 5 de julio de 2010, identificador microjuris MJJ24135; Corte de Apelaciones de Santiago, Rol Reforma Laboral No 728-2010, 27 de agosto de 2010, identificador microjuris MJJ24676; Corte de Apelaciones de Santiago, Rol Reforma Laboral No 158-2014, 10 de julio de 2014, identificador microjuris MJJ38211.
} 
trabajo, no debiendo pagar el empleador las remuneraciones durante los días de ausencia al trabajo ${ }^{122}$.

Una segunda posición señala que la ausencia al trabajo que legitima el término de la relación laboral es solamente la que carece de justificación. Agrega, que la detención de un trabajador ordenada por un juez impide concurrir al desempeño de su actividad por una circunstancia ajena a su voluntad, como consecuencia de un acto de autoridad ejercido por un funcionario público, con caracteres de imprevisto e irresistible ${ }^{123}$, más aun cuando el trabajador es absuelto posteriormente de los cargos formulados en su contra y que motivaron su privación de libertad por sentencia ejecutoriada ${ }^{124}$. De este modo, es un caso fortuito el que impide concurrir al trabajo, estando justificada la ausencia al trabajo ${ }^{125}$.

Un tercer sector de la jurisprudencia ${ }^{126}$ es del criterio que si el trabajador faltó a sus labores por haber sido detenido legalmente por la autoridad correspondiente y privado de libertad por la judicatura (prisión preventiva en el actual proceso penal), habiéndosele imputado la comisión de un delito, tal ausencia es injustificada. Ello porque la acción voluntaria del trabajador que ha llevado a que un juez haya decretado su privación de libertad si bien es irresistible, no es imprevisible, toda vez que el trabajador debió prever las consecuencias penales y procesales de su actuar. No se trata que los jueces con competencia en lo laboral resuelvan o anticipen juicios que son de índole penal, tarea que le corresponde a los jueces que conozcan del proceso criminal respectivo, pero ciertamente, a la hora de decidir si probada la ausencia a sus labores está justificada, necesariamente debe el tribunal laboral entender que la prisión preventiva u otra medida cautelar privativa de libertad decretada por un juez penal nunca puede ser justificante de la inasistencia, sea cual fuere el resultado posterior del juicio penal, pues no es dable exigirle al empleador que haga una

\footnotetext{
122 IRURETA (2013 c), p. 53.

${ }^{123}$ Corte de Apelaciones de San Miguel, 6 de mayo de 1996, RDJ, T. XCIII, $2^{\text {a }}$ parte, sección $3^{\text {a }}$ (1996), pp. 99-100;

${ }^{124}$ Corte Suprema, 2 de noviembre de 1999, RDJ, T. XCVI, $2^{\text {a }}$ parte, sección $3^{\text {a }}$ (1999), pp. 223-224; Corte de Apelaciones de Santiago, 27 de diciembre de 2000, GJ No 247 (2001), pp. 208-209.

125 García (1997), p. 67.

${ }^{126}$ Corte Suprema, 23 de abril de 1986, RFM No 329, 1986, pp. 171-172; Corte Suprema, 4 de enero de 1995, RDJ, T. XCII, $2^{\text {a }}$ parte, sección 3a ${ }^{\text {a }} 1995$, p. 11; Corte de Apelaciones de Santiago, 4 de junio de 1998, GJ No 216, 1998, p, 197; Corte Suprema, 2 de agosto de 1999, RFM No 489, 1999, pp. 1796 -1797; Corte Suprema, 4 de septiembre de 2003, RDJ, T. C, $2^{\text {a }}$ parte, sección 3a , 1999, pp. 150-151; Corte Suprema, 6 de enero de 2004, GJ No 283, 2004, p. 280; Corte Suprema, 17 de agosto de 2006, RFM No 536 (2005-2006), p. 2213; Corte de Apelaciones de Santiago, 25 de octubre de 2005, GJ No 304, (2005), pp. 319-320; Corte Suprema, 29 de noviembre de 2005, RFM № 539, (2005-2006), p. 3149; Corte Suprema, Rol No 3547-2010, 29 de julio de 2010, identificador microjuris MJJ243659.
} 
suerte de adivinación acerca de lo que finalmente decidirá la justicia del crimen o que espere hasta que exista sentencia ejecutoriada al respecto.

La disparidad de criterios se debe a que no existe una norma legal que regule orgánicamente la suspensión del contrato individual de trabajo, que contemple la privación de libertad del trabajador en virtud de una resolución no condenatoria como supuesto de suspensión del contrato de trabajo. Situación distinta a la que existe en la legislación laboral española, donde expresamente se contempla la privación de libertad sin sentencia condenatoria como causa de suspensión de la relación laboral' ${ }^{127}$.

En lo que sí no existe controversia es que condenado el trabajador a una pena privativa de libertad en virtud de una sentencia judicial firme y ejecutoriada por delitos no cometidos con ocasión del trabajo, es ajustada a derecho la extinción del contrato de trabajo por despido disciplinario fundado en la causal del artículo $160 \mathrm{~N}^{\circ} 3$ del Código del Trabajo. Ello porque se establece mediante una decisión con autoridad de cosa juzgada la culpabilidad del trabajador en la comisión del hecho ilícito, desapareciendo la función de la presunción de inocencia, y la inimputabilidad de la imposibilidad de concurrir al trabajo ${ }^{128}$.

\subsection{Ilícitos penales y faltas laborales}

En situación diversa se encuentra la posible subsistencia de una responsabilidad penal por comportamientos que afectan la prestación laboral, los cuales, considerando la normativa contractual e interna del empleador, configuran también un incumplimiento laboral. Se trata de conductas que pueden originar, a la vez, responsabilidad penal y disciplinaria para el trabajador, comprendiéndose figuras tales como: la riña (dentro del lugar en que se encuentra la empresa), el comportamiento dañoso de bienes de la empresa, el hurto, el fraude, la injuria, las lesiones, las conductas de carácter sexual, la muerte de personas a su cargo. El problema que surge es que no existe claridad en la forma en que debe proceder el empleador en estas situaciones, esto es, si puede iniciar un procedimiento disciplinario e imponer una sanción sin esperar la condena penal o, por el contrario, debe esperar que se condene penalmente al trabajador delincuente para recién imponer una sanción laboral por los mismos hechos.

Una primera respuesta posible es que se suspende la iniciación del procedimiento disciplinario y, consiguientemente, la materialización de la responsabilidad disciplinaria mientras el trabajador dependiente no sea condenado

127 Dispone el artículo 45 del Estatuto de los Trabajadores: "Causas y efectos de la suspensión. 1. El contrato de trabajo podrá suspenderse por las siguientes causas: [...] g) Privación de libertad del trabajador, mientras no exista sentencia condenatoria".

128 García (1997), pp. 69-70. 
penalmente mediante sentencia judicial con autoridad de cosa juzgada ${ }^{129}$. Ello fundado sobre la base de la vigencia en el contrato de trabajo del principio de presunción de inocencia que rige en materia penal y de la consideración que el empleador no puede arrogarse el derecho a imponer vía anticipada una pena, en este caso, de carácter privado ${ }^{130}$, temporalmente antes que el mismo poder estatal.

La segunda respuesta es totalmente diversa. Es posible advertir cómo la conducta en análisis tiene un carácter de pluriofensividad, al afectar la organización de la empresa, protegida por la normativa laboral, e intereses sociales y generales, que tutela el Derecho Penal, pudiendo simultáneamente solicitar el empleador una reacción general de parte del ordenamiento estatal e imponer una sanción laboral, por cuanto se trata de una conducta que configura una falta laboral que existe independiente del ilícito penal ${ }^{131}$. Al tratarse de una infracción autónomamente perseguible por parte del empleador, se prescinde de la presunción de inocencia que impera en el ámbito penal, cuya vigencia en el derecho disciplinario laboral es negada ${ }^{132}$. Estas consideraciones excluyen una relación de prejudicialidad entre el juicio penal y la acción disciplinaria laboral por la misma falta, reconociéndosele así al empleador la posibilidad de reaccionar, en términos de inmediatez exigidos por el ordenamiento jurídico laboral frente a una falta laboral.

Vale sin reserva alguna la regla que la conducta que constituye una falta laboral es independientemente de la existencia o configuración de un delito ${ }^{133}$, moviéndose en dos planos distintos, sin que se complementen, debido a que

\footnotetext{
129 Montuschi (1973), p. 176.

130 Numerosos autores califican las sanciones disciplinarias como penas privadas, pudiendo mencionarse: MonstusChi (1991), p. 21; MacChiavello (1986), p. 253; FernÁNDeZ (1991), p. 236; Mainardi (2002), p. 170; Di Paola (2010), pp. 13-14; RodríGuez (2008), p. 183; Mainardi (2012), p. 92.

131 Santana (2001), p. 63; Mainardi (2002), pp. 134 ss.; Di Paola (2010), pp. 241 ss.; Castro (1993), pp. 121-123; RodríGuez (2008), p. 85; PoQuet (2011), p. 119.

132 MaInardi (2002), p. 134.

133 Se ha resuelto que la responsabilidad disciplinaria del trabajador es independiente de la responsabilidad penal, no siendo necesario una condena penal para aplicar una sanción disciplinaria, debido a que las faltas laborales se configuran en forma independiente a los delitos. En este sentido: Corte Suprema, 23 de junio de 1980, RDJ, T. LXXVII, 2a parte, sección $3^{a}$ (1980), pp. 53-54; Corte de Apelaciones de Santiago, 30 de enero de 1989, RDJ, T. LXXXVI, $2^{\text {a }}$ parte, sección $3^{\text {a }}$ (1989), p. 44; Corte de Apelaciones de Santiago, 26 de octubre de 1989, GJ № 112 (1989), p. 109; Corte Suprema, 14 de junio de 1994, RDJ, T. XCl, $2^{\text {a }}$ parte, sección $3^{\text {a }}$ (1994), p. 92; Corte de Apelaciones de Santiago, 12 de septiembre de 1997, GJ № 207 (1997), p. 183; Corte Suprema, Rol № 272-2010, 15 de abril de 2010, identificador LegalPublishing CL/JUR/17017/2010; Corte de Apelaciones de Santiago, Rol Reforma Laboral № 1786-2013, 7 de mayo de 2014; Corte de Apelaciones de Santiago, Rol Reforma Laboral No 1926-2013, 5 de junio de 2014; Corte de Apelaciones de Temuco, Rol Reforma Laboral $N^{\circ}$ 86-2014, 11 de junio de 2014; Corte de Apelaciones de Santiago, Rol Reforma Laboral № 19262013, 5 de junio de 2014, que señala: " $5^{\circ}$ [...] caber tener en cuenta que la responsabilidad laboral y
} 
derivan sus configuraciones de la violación de normas diversas, que forman parte de diferentes ordenamientos, uno penal y el otro laboral ${ }^{134}$. De ahí, que es irrelevante para los efectos de la evaluación de la proporcionalidad de la sanción laboral el hecho que el incumplimiento laboral constituya, a la vez, ilícito penal, siendo relevante la idoneidad de la conducta que niega el elemento fiduciario de la relación de trabajo ${ }^{135}$.

El empleador, por tanto, puede autónomamente proceder a ejercitar el poder disciplinario sin preocuparse del desarrollo del procedimiento penal cuando la falta laboral se configura independientemente de la existencia o no de un ilícito penal ${ }^{136}$. Lo que trae como consecuencia que, aun cuando sea absuelto el trabajador en sede penal la falta laboral se configura y su castigo es válido, por no requerir la existencia de la falta laboral la configuración de un delito ${ }^{137}$.

Diversa es la situación de las faltas laborales, que se encuentren descritas en el reglamento interno, en otros cuerpos normativos internos o en el contrato de trabajo, que exigen para su configuración la comisión de delitos descritos en el Código Penal o leyes especiales, caso en el cual el ilícito penal forma parte como elemento constitutivo del incumplimiento laboral. En este supuesto solamente la declaración de existencia del delito penal mediante sentencia penal con efecto de cosa juzgada legitima al empleador a ejercer el poder disciplinario, puesto que la falta laboral solamente existe si se configura el delito penal, el cual únicamente será tal cuando la justicia criminal lo declara así por decisión con autoridad de cosa juzgada ${ }^{138}$. Antes no existe la falta laboral, debido a que no existe delito penal, toda vez, que el trabajador dependiente, como todo ciudadano goza de la presunción de inocencia, estatus que cesa con la condena penal firme.

la criminal son independientes por lo que lo decidido en un ámbito no significa, per se, que lo mismo debe resolverse en la otra sede o que la sustituya".

134 MaINARDI (2002), p. 135.

135 MaINARDi (2002), p. 135.

136 Di PAOLA (2010), p. 241.

137 Corte de Apelaciones de Santiago, 12 de diciembre de 1984, GJ № 54 (1984), p. 154; Corte de Apelaciones de Santiago, 30 de enero de 1989, GJ № 103 (1989), p. 83; Corte de Apelaciones de Santiago, 12 de septiembre de 1997, GJ № 207 (1997), p. 183, que sostiene: "3º) [...] se ha configurado su respecto la causal de caducidad del contrato invocado por la actora [...] en nada altera tal conclusión la circunstancia que en la causa criminal incoada en su contra y traída a la vista, se haya dispuesto la libertad de la empleada, por falta de méritos, por cuanto como se ha sostenido invariablemente por la jurisprudencia, una cosa es la responsabilidad penal y otra su responsabilidad laboral derivada del contrato de trabajo que ha vinculado a las partes, bastando aquí que los antecedentes demuestren que en realidad se tuvo un comportamiento incorrecto o falto de probidad"; Corte Suprema, Rol № 2722010, 15 de abril de 2010, identificador LegalPublishing CL/JUR/17017/2010.

${ }_{138}$ MAINARDI (2002), pp. 135-136. 


\section{La relevancia del elemento subjetivo en la configuración de la falta laboral}

La configuración de la falta laboral hasta ahora considerada exige como elemento constitutivo de carácter objetivo: la infracción por parte del trabajador de las obligaciones y/o prohibiciones previamente establecidas en alguno de los instrumentos que corresponda. Sin embargo, surge el problema de conocer cuál es la relevancia de la voluntariedad en la ejecución de la conducta por parte del dependiente. Debiéndose determinar si su existencia en el ordenamiento jurídico laboral nacional es el elemento subjetivo necesario y de la existencia de la falta laboral o, por el contrario, solamente es un elemento que debe considerarse para los efectos de calificar la gravedad de la falta laboral, bastando para la existencia de ésta solamente la vulneración de las normas de conducta que debe observar el trabajador. En otros términos, la duda que surge es si para estar en presencia de una falta laboral basta solamente el elemento objetivo, que es la infracción de una obligación o prohibición laboral o, también, es necesario el elemento subjetivo, constituido por el dolo o la culpa del trabajador. Cuestión que es ampliamente discutida en el derecho comparado, que es donde se ha planteado especialmente la discusión al respecto ${ }^{139}$.

Una posición minoritaria de la doctrina niega que el elemento subjetivo forme parte de la estructura de la falta laboral ${ }^{140}$, como elemento de existencia de la misma. Opinión que parte de una concepción neutra y objetiva de la prestación laboral y de los deberes laborales del trabajador. La culpabilidad, para esta posición, no constituye un requisito de existencia de la falta laboral, bastando para su configuración únicamente la infracción por parte del trabajador de las obligaciones y/o prohibiciones que debe observar. Ello, por cuanto, la violación de las reglas que regulan la ejecución de la prestación de trabajo y la vida del dependiente en el lugar de trabajo determinan siempre una desviación del estándar de ejecución de la prestación, de ahí, que el incumplimiento prescinde de la culpabilidad como vicio de la voluntad. Agrega, que el elemento subjetivo de la culpabilidad solamente es relevante para la calificación de la gravedad de la falta laboral. Por tanto, la culpabilidad, según esta concepción, solamente será elemento de existencia del incumplimiento laboral cuando la ley, el reglamento interno, el reglamento de higiene y seguridad en el trabajo, el contrato individual de trabajo, el instrumento colectivo o el cuerpo normativo

139 Véanse para el derecho italiano especialmente: MANCINI (1957), p. 25; MontusCHI (1973), p. 119; MaInARDI (2002), pp. 136 ss.; Dı PAOLA (2010), pp. 50 ss. Para el derecho español véanse especialmente: Fernández (1991), pp. 182 ss.; CAstro (1993), pp. 180-185; Rodríguez (2008), p. 87; Poquet (2011), pp. 190-194.

140 Véase un resumen de esta doctrina en: MAINARDI (2002), pp. 138 ss. Véase igualmente: Dı PaOlA (2010), pp. 50 y ss. 
a que se remiten estos instrumentos exigen dolo o culpa al individualizar las obligaciones, prohibiciones y/o faltas laborales ${ }^{141}$.

En esta concepción, la culpabilidad disciplinaria no resulta diversa de aquella contractual, en cuando el dependiente ante una situación de incumplimiento por el hecho que la prestación no es ejecutada o es deficientemente ejecutada, releva en la misma una cualificación subjetiva culpable. La negligencia coincide, simplemente, con la inadecuada actividad. En fin, concluye que solamente una voluntaria desviación de la regla de ejecución de la prestación puede dar lugar a la responsabilidad disciplinaria ${ }^{142}$.

Sin embargo, la opinión contraria y predominante en la doctrina es que la conducta del trabajador, que forma parte integrante de la falta laboral, para ser susceptible de sanción debe ir acompañada siempre del elemento subjetivo ${ }^{143}$, siendo, por tanto, necesario al menos un comportamiento culposo, del cual no es posible prescindir, al contrario de lo que ocurre con otros factores, como lo son la existencia de una daño o su entidad, los que solamente tienen relevancia para calificar la gravedad de la falta laboral a fin de determinar la sanción laboral que corresponde aplicar ${ }^{144}$. Si la responsabilidad disciplinaria del trabajador es de carácter personal, junto con la existencia del hecho objetivo encuadrable en el incumplimiento laboral debe determinarse su imputación al trabajador (dolo o culpa), como también el grado de culpabilidad, circunstancia esta última que tiene relevancia, también, para determinar la proporcionalidad entre la falta y la sanción impuesta ${ }^{145}$.

La culpabilidad puede identificarse con la negligencia del trabajador, la impericia o la negativa injustificada de observar las disposiciones e instrucciones impartidas por el empleador o por sus colaboradores, con el comportamiento dolosamente tenido en la conducta lesiva de los intereses protegidos con el sistema disciplinario ${ }^{146}$, con la conducta maliciosa. La inmanente presencia del elemento subjetivo en la definición de la falta laboral se encuentra en muchas cláusulas contractuales y normas internas elaboradas por el empleador, en las

\footnotetext{
141 MANNACIO (2001), p. 835; Assanti (1963), p. 101, tratando el incumplimiento contractual, sostiene que es necesario el elemento de la voluntad sólo para el caso de la sanción extintiva de la relación de trabajo.

142 Mainardi (2002), p. 138.

143 Mancini (1957), p. 25; Montuschi (1973), p. 119; Luque (1999), p. 465; Santana (2001), p. 61; Di Paola (2010), p. 51. Fernández (1991), pp. 182 ss.; Castro (1993), p. 180; RodríGuez (2008), p. 87; PoQuet (2011), p. 190.

144 Fernández (1991), pp. 182 ss.; Mainardi (2002), pp. 136 ss.

145 Fernández (1991), pp. 182 ss.; Mainardi (2002), pp. 136 ss.

146 Fernández (1991), pp. 182 ss.; Mainardi (2002), pp. 137 ss.
} 
cuales se contempla la culpa de forma explícita o implícita como elemento constitutivo de la falta laboral.

Sin perjuicio que la discusión existente en la doctrina comparada puede plantearse, igualmente, en nuestro ordenamiento jurídico, por ser las normas similares, prima la tesis que toda falta laboral no solo debe ser imputable al trabajador sino que, además, debe ser ejecutada voluntariamente por éste ${ }^{147}$, siendo, por tanto, la culpabilidad un elemento de existencia del incumplimiento laboral. Siguiendo la doctrina comparada, al compartir la responsabilidad disciplinaria del trabajador ciertos elementos con la responsabilidad penal, siendo frecuente la utilización de elementos de esa última para sancionar al trabajador, debe recurrirse, también, a la noción de culpabilidad del Derecho Penal, de la teoría más clásica, que concibe la culpabilidad como la capacidad del sujeto para haber obrado de forma distinta a como lo hizo, la que, precisamente, permite formular reproche a su conducta ${ }^{148}$. Y todo ello en su doble vertiente, malicia y negligencia.

Esta posición es más ajustada a la naturaleza del poder disciplinario, cuyo ejercicio permite imponer al trabajador infractor una sanción laboral, como castigo a una falta laboral ${ }^{149}$. Hace surgir una responsabilidad personal con una finalidad punitiva, en la que queda al margen la consideración del daño ocasionado al empleador. Solamente desconociendo la naturaleza de la responsabilidad disciplinaria del trabajador puede negarse que en la base de la sanción impuesta subyace la idea de castigo al culpable y de prevención de otras infracciones laborales futuras del mismo infractor o de sus compañeros de trabajo ${ }^{150}$.

En la responsabilidad disciplinaria resulta inevitable e imprescindible tomar en especial consideración la conducta del trabajador, porque sólo puede concebirse una sanción laboral frente al trabajador que se hizo merecedor de ella por una actuación querida o, en todo caso, no evitada estando en condiciones de hacerlo. De este modo, la conducta laboral, solamente se podrá sancionar cuando sea negligente o maliciosa, excluyendo la sanción en los supuestos en que le es imposible al trabajador obrar de otro modo.

En la jurisprudencia judicial, por su parte, se comparte esta posición de la necesaria voluntariedad de la conducta del trabajador para que pueda ser sancionada. Es esta la concepción consolidada en nuestros Tribunales de Justicia en relación al despido disciplinario. Conclusiones que pueden ser extendidas

\footnotetext{
147 IRUReta (2013 b), p. 163.

148 FERNÁNDEZ (1991), p. 182.

149 LUQUe (1999), p. 465.

150 FERNÁNDEZ (1991), p. 182.
} 
a las sanciones conservativas del contrato individual de trabajo dada su generalidad. De la jurisprudencia de los Tribunales de Justicia se deduce que para calificar el despido se realiza una valoración de la conducta del sujeto, de su conciencia y voluntariedad, que le permitía al trabajador optar por una conducta distinta. Es así, que se ha resuelto que las causales del despido disciplinario exigen para su configuración a lo menos un grado de culpabilidad por parte del trabajador despedido, en tanto éste debe ser considerado en sus particularidades individuales, conforme al criterio normativo que exigen las causales de despido disciplinario, las que afirman en sí la posibilidad de determinar si aquél considerado individualmente podía o no actuar de otra manera y en qué grado, pues, sólo de ese modo se logra determinar si el trabajador defraudó o no las expectativas que a su respecto confiaba el empleador ${ }^{151}$.

Igualmente, existen otras afirmaciones jurisprudenciales que evidencian el alto grado de subjetividad que caracteriza a la responsabilidad disciplinaria. De este modo, las agravantes o atenuantes empleadas con mayor frecuencia por los Tribunales de Justicia demuestran cómo queda impregnado todo su régimen jurídico con este rasgo: la antigüedad del trabajador ${ }^{152}$, la buena conducta que haya observado anteriormente ${ }^{153}$, el tipo de empresa de que se trata o actividad que desarrolla ${ }^{154}$, el tipo de cargo o el rango jerárquico que el trabajador sancionado ocupa en la empresa ${ }^{155}$, la reiteración de la conducta ${ }^{156}$, la reincidencia

151 Corte de Apelaciones de Santiago, Rol Reforma Laboral No 732-2012, 2 de octubre de 2012. En igual sentido: Corte de Apelaciones de Santiago, Rol Reforma Laboral № 1639-2011, 17 de mayo de 2012, identificador microjuris MJJ31902, que sostiene a propósito del despido disciplinario: "los hechos invocados por la demandada para la desvinculación del actor y que dicen relación con los atrasos reiterados, para configurar la causal esgrimida, deben revestir una gravedad tal que produzcan el quiebre del vínculo, es decir, el incumplimiento ha de ser de trascendencia negativa, de mucha entidad o importancia, de manera tal que perturbe sensiblemente el normal funcionamiento de la empresa, y requiere para su calificación, una contextualización fáctica, que además, debe estar absolutamente vinculado con la intencionalidad del trabajador, siendo necesario, entonces, que el acto o conducta sea atribuible a dolo o negligencia inexcusable de aquél".

152 Corte de Apelaciones de Santiago, 23 de septiembre de 1986, GJ № 75 (1986), p. 68; Corte de Apelaciones de Valparaíso, Rol Reforma Laboral № 78-2013, 8 de abril de 2013; Corte de Apelaciones de Valparaíso, Rol Reforma Laboral № 133-2014, 20 de mayo de 2014; Corte de Apelaciones de San Miguel, Rol Reforma Laboral № 200-2013, 10 de julio de 2013; Corte de Apelaciones de Santiago, Rol Reforma Laboral № 989-2014, 28 de noviembre de 2014,

153 Corte de Apelaciones de Santiago, 8 de julio de 2003, RFM No 514 (2003), p. 2504; Corte de Apelaciones de Copiapó, Rol Reforma Laboral № 73-2012, 18 de marzo de 2013; Corte de Apelaciones de Santiago, Rol Reforma Laboral № 1170-2013, 10 de diciembre de 2013.

154 Juzgado de Letras del Trabajo de Antofagasta, RIT O-815-2012, 17 de enero de 2014.

155 Corte de Apelaciones de Santiago, Rol Reforma Laboral No 1750-2013, 8 de mayo de 2014; Corte de Apelaciones de Iquique, Rol Reforma Laboral № 33-2014, 18 de julio de 2014.

156 Corte de Apelaciones de Santiago, Rol Reforma Laboral № 1225-2012, 27 de noviembre de 2012; Primer Juzgado de Letras del Trabajo de Santiago, RIT O-1641-2013, 5 de agosto de 2013, identifi- 
de la conducta sancionada ${ }^{157}$, etc. Todas estas circunstancias, especialmente los antecedentes propios del trabajador, demuestran que la responsabilidad disciplinaria alcanza su máxima subjetivación.

En conclusión, en el ordenamiento jurídico laboral nacional puede afirmarse que la responsabilidad disciplinaria del trabajador se funda en la culpabilidad, que necesariamente presupone una capacidad volitiva del trabajador, debiendo existir una imputabilidad subjetiva en el incumplimiento laboral.

Atendido que la culpabilidad es un elemento subjetivo, su concurrencia emana de las circunstancias en que se ejecuta la conducta sancionada, que permiten excluir que el trabajador haya estado en la imposibilidad de obrar de otro modo. De esta forma, su determinación debe ser efectuada en base a una noción objetiva y no meramente psicológica de la culpabilidad, en base a la ordinaria diligencia que debe emplear el trabajador al ejecutar sus labores y satisfacer el interés del empleador ${ }^{158}$.

Salvo excepciones, la voluntariedad no supone la concurrencia de un dolo específico en la ejecución de la conducta, ya que la regla general en materia de responsabilidad disciplinaria es que la acción reprochada no se haya ejecutado con un especial ánimo de provocación del ilícito, bastando la culpa o negligencia ${ }^{159}$. Solamente será necesario la concurrencia del dolo, de una intencionalidad especial o de un cierto tipo de negligencia calificada, cuando la ley, el reglamento interno, el reglamento de higiene y seguridad en el trabajo, el instrumento colectivo o el contrato individual de trabajo al establecer tanto las obligaciones y prohibiciones que debe observar el trabajador como las faltas laborales la exigen para su configuración, caso en el cual, necesariamente debe concurrir el tipo de culpabilidad especial que exige la norma.

Tratándose del despido disciplinario, existen diversas causales contenidas en el artículo 160 del Código del Trabajo que al tipificar las faltas laborales que permiten su aplicación, exigen un dolo o intencionalidad especial, no bastando la mera voluntariedad del trabajador ni cualquier grado de negligencia. Así, tratándose de las injurias proferidas por el trabajador al empleador (artículo 160 № 1 letra d] del Código del Trabajo), se exige que en la ejecución del acto injurioso no sólo concurra la voluntariedad sino que,además, es indispensable

cador LegalPublishing CL/JUR/3143/2013; Segundo Juzgado de Letras del Trabajo de Santiago, RIT O-4027-2013, 25 de febrero de 2014; Corte de Apelaciones de Iquique, Rol Reforma Laboral No 33-2014, 18 de julio de 2014.

157 Corte de Apelaciones de Valparaíso, Rol Reforma Laboral № 339-2012, 19 de noviembre de 2012; Corte de Apelaciones de Santiago, Rol Reforma Laboral No 630-2012, 4 de noviembre de 2012; sentencia de la Corte de Apelaciones de Santiago, Rol Reforma Laboral № 316-2014, 29 de agosto de 2014.

158 Di PaOla (2010), pp. 51 ss.

159 Para el despido disciplinario véase: IRURETA (2013 a), p. 163. 
un claro animus injuriandi $i^{160}$ en el trabajador. La concurrencia de este ánimo es esencial, pues, en definitiva, es el elemento subjetivo indispensable para configurar la falta laboral tipificada en el artículo $160 \mathrm{~N}^{\circ} 1$ letra d) del Código del Trabajo que da lugar a la aplicación del despido disciplinario. Lo mismo ocurre con la causal del artículo $160 \mathrm{~N}^{\circ} 6$ del Código del Trabajo, que permite materializar el despido disciplinario debido a la conducta del trabajador que produce un "perjuicio material causado intencionalmente en las instalaciones, maquinarias, herramientas, útiles de trabajo, productos o mercaderías". Se trata de una norma amplia, que pone el acento en la intencionalidad, y que pretende sancionar los perjuicios que sufre el empleador a raíz de las acciones dolosas del trabajador. "De esta forma, en la ocurrencia de la hipótesis establecida en el artículo $160 \mathrm{~N}^{\circ} 6$ del Código del Trabajo debe concurrir un dolo genérico que refleje conocimiento y voluntad de provocar un perjuicio material en bienes muebles o inmuebles del empleador (animus dommandi o nocendi $i^{\prime \prime 161}$. Respecto de la causal de despido del artículo 160 № 5 se exige para su configuración que

\footnotetext{
160 Véase IRURETA (2012 b), p. 98. Se ha señalado al respecto: "la concurrencia de un acto injurioso requiere no solo de voluntariedad sino que, además, de un claro animus injuriandi. La concurrencia de este ánimo es esencial, pues en definitiva ello permitirá resolver el verdadero sentido o alcance de expresiones aparentemente injuriosas. Como se ha dicho en materia penal, pero aplicable a la esfera laboral, el simple proceso de constatación de hechos no basta, ya que sobre el sentido literal de las palabras debe prevalecer la intención con que ellas se pronuncian. En consecuencia, cuando se intenta aplicar la causal de injurias ella termina enfocándose hacia toda falta de respeto, ejecutadas en forma despectiva, despreciativa y altamente ofensiva, con el expreso ánimo de injuriar. Y si falta ese ánimo, difícilmente podrá configurarse la causal. Ese sería el caso, por ejemplo, de las palabras aparentemente injuriosas pronunciadas por un trabajador extranjero que desconoce los alcances del idioma, o el supuesto de la ofensa originada en una agresión previa al trabajador en la cual se busca responder a una provocación más que desplegar un determinado animus. También harían desaparecer la ilicitud de la expresión cuando esta es proferida en razón de un deseo de divertir, de corregir o bien de informar o aconsejar, entre otros [...]. En materia laboral, la exigencia de un especial ánimo de injuria se ha estructurado como un requisito ampliamente asumido por la jurisprudencia aun cuando de calificación más flexible que la exigida en el ámbito penal. Lo anterior no implica que la ofensa deba estar desprovista de un especial ánimo de injuriar; simplemente, la valoración de ese ánimo así como la configuración de la infracción tiende a ser en la práctica técnicamente menos rigurosa que aquella que se ocupa en sede penal". IrURETA (2012 b), pp. 98 ss.

161 IRURETA (2013 a), p. 164. Se agrega por el autor citado: "Si no se exigiese intencionalidad, entonces sería factible alegar que los meros descuidos, las negligencias simples o las desidias del trabajador no deben ser soportados por el empleador en virtud de la ajenidad. [...] Claramente, la redacción utilizada por el Código no pretende asimilar el dolo penal con la voluntariedad de la conducta ilícita laboral. Como ya se ha dicho, la causal del artículo 160 NN$^{\circ} 6$ CT no implica la comisión de un delito penal de daño. Por el contrario, lo que subyace en la norma del Código del Trabajo es una intención lesiva que la mayor parte de las veces será evaluada por la magnitud del daño. De igual forma, la presencia de un dolo perjudicial no exige la concurrencia de un ánimo de venganza. Tampoco se requiere una especial intención de impedir el ejercicio del poder de dirección por parte del empleador. Más aún, perfectamente el daño se puede provocar por simple diversión, o por pura maldad. Lo relevante es que exista intencionalidad (no mera imprudencia) en la comisión del acto perjudicial, cuestión que permite vincular la causal disciplinaria con una típica hipótesis de mala fe subjetiva". IRURETA (2013 a), pp. 164 ss.
} 
los hechos ejecutados por el dependiente sean extremadamente imprudentes o con una negligencia considerable ${ }^{162}$.

En las restantes causales de despido disciplinario las conductas que las configuran pueden ser dolosas o culpables, aunque tratándose de la falta de probidad del trabajador en el desempeño de sus funciones (artículo $160 \mathrm{~N}^{\circ} 1$ letra a] del Código del Trabajo) y la prohibición de competencia desleal (artículo $160 N^{\circ} 2$ del Código del Trabajo), en que la conducta indebida será generalmente dolosa o al menos de mala fe, debido a que la estructura de estas faltas laborales exige una conducta realizada por el trabajador con plena voluntad y conciencia sobre su carácter infractor del contrato de trabajo.

No obstante la necesaria concurrencia de la culpabilidad para estar en presencia de una falta laboral, tanto al momento de aplicarse una sanción disciplinaria como el momento de acreditarse su existencia ante el órgano competente que conoce de la impugnación de la sanción, no se exige una prueba especial para acreditar la culpabilidad. Así las cosas, el incumplimiento por parte del trabajador de sus obligaciones y prohibiciones legales, convencionales o reglamentarias, de cualquier modo que haya ocurrido, genera responsabilidad disciplinaria, salvo que se acredite por el trabajador una causal exculpatoria ${ }^{163}$. Al empleador siempre corresponde acreditar el elemento objetivo del incumplimiento laboral (la conducta del trabajador que lo configura) y los elementos fácticos que ponen de manifiesto su gravedad (reiteración, amonestaciones previas, resultados lesivos, perjuicio patrimonial, etc.). Salvo excepciones (por ejemplo, las faltas laborales que exigen una conducta maliciosa o conducta inexcusable), la noción de culpabilidad no juega en el instante de la configuración de la falta laboral ninguna función, y solamente si el trabajador introduce elementos que acreditan su exculpación, podrá discutirse el grado de culpabilidad y la culpabilidad misma ${ }^{164}$ para determinar la configuración de la falta laboral. En los demás casos, la acreditación de la culpabilidad se integra a los elementos que cumplen la función de graduar la gravedad de la falta laboral y

162 Corte Suprema, Rol № 292-2013, 23 de mayo de 2013, sostiene: "[... Se trata de una causal subjetiva y supone en primer término que los hechos ejecutados por el dependiente sean extremadamente imprudentes o con una negligencia considerable. No se requiere entonces una intencionalidad especial, sino un olvido inexcusable de las precauciones que la prudencia común aconseja y que conduce a la realización de hechos que, de mediar malicia, constituirían delito".

163 Gómez (2009), p. 94. Se ha declarado justificado el despido cuando el trabajador no ha acreditado una causal eximente del incumplimiento contractual: Corte de Apelaciones de Santiago, 23 de septiembre de 1986, GJ No 75 (1986), p. 68; Corte Suprema, 31 de marzo de 2004, GJ № 286 (2004), pp. 300301. Y se ha declarado injustificado el despido cuando el trabajador acredita una eximente, como legítima defensa: Corte de Apelaciones de Santiago, Rol Reforma Laboral № 1.524-2014, 5 de enero de 2015; Corte de Apelaciones de Santiago, Rol Reforma Laboral № 1.685-2014, 28 de enero de 2015.

164 Gómez (2009), p. 94. 
la proporcionalidad de la sanción con que ha sido castigada, es decir, es uno de los antecedentes a considerar en el juicio de proporcionalidad, tanto en el realizado por el empleador como por el órgano que conoce de la impugnación de la sanción ${ }^{165}$. Es en los juicios de impugnación del despido disciplinario donde mayor trascendencia ha tenido la culpabilidad, considerándose por el juez como elemento para calificar la gravedad de la falta laboral sancionada, declarándose justificado el despido cuando junto a otros antecedentes concurre la negligencia ${ }^{166}$, falta de diligencia debida ${ }^{167}$ o malicia ${ }^{168}$, y declarándose injustificado cuando no concurre la culpabilidad ${ }^{169}$.

Ahora bien, como la culpabilidad es un elemento subjetivo, la prueba que se rinde para acreditar su concurrencia no es directa, comprobándose los antecedentes que conducen a establecerla, como lo es el cargo, la reiteración de la conducta, la capacitación oportuna, el conocimiento de las normas de conducta que transgrede.

\section{Conclusiones}

La determinación de la noción de falta laboral es de mucha relevancia, porque solamente cuando se está en presencia de la misma el empleador puede legítimamente ejercer el poder disciplinario de que está dotado. Por el contrario, si la conducta del trabajador dependiente no se encuadra en el concepto de falta laboral, la misma no puede ser castigada por el empleador, al carecer el poder disciplinario de su presupuesto de ejercicio.

En la legislación laboral nacional no existe definición alguna de falta laboral. Sin embargo, teniendo presente la regulación jurídica del poder disciplinario, es posible conceptualizar la falta laboral como la conducta observada por el

\footnotetext{
165 LUJÁN (1997), pp. 23 ss.

166 Corte Suprema, Rol No 232-2010, 24 de marzo de 2014, identificador microjuris MJJ23033 Segundo Juzgado de Letras del Trabajo de Santiago, RIT O-1579-2012, 16 de agosto de 2012; Corte Suprema, Rol № 1721-2012, 5 de octubre de 2012; Juzgado de Letras del Trabajo de Chillán, RIT O-254-2013, 29 de abril de 2014.

167 Corte de Apelaciones de Antofagasta, Rol No 195-2009, 12 de marzo de 2010, identificador microjuris MJJ23165.

168 Véanse: Corte Suprema, 23 de mayo de 2013, Rol № 292-2013, 23 de mayo de 2013; Corte de Apelaciones de Valparaíso, Rol Reforma Laboral № 85-2014, 2 de abril de 2014; Corte de Apelaciones de Valparaíso, Rol Reforma Laboral № 76-2014, 9 de mayo de 2014; Corte de Apelaciones de Valparaíso, Rol Reforma Laboral № 84-2014, 12 de mayo de 2014; Corte de Apelaciones de Concepción, Rol Reforma Laboral № 326-2014, 17 de diciembre de 2014. Todas sentencias recaídas en juicios donde se discute la configuración de la causal de despido del artículo 160 № 5 del Código del Trabajo, que emplea la expresión "imprudencias temerarias".

169 Corte de Apelaciones de Santiago, Rol Reforma Laboral № 1639-2011, 17 de mayo de 2012, identificador microjuris MJJ31902.
} 
trabajador dependiente en el contexto de la relación laboral que provoca la transgresión de alguna obligación o prohibición consignada previamente de forma legítima en el contrato individual de trabajo, en el reglamento interno, en el reglamento de higiene y seguridad en el trabajo, en el instrumento colectivo de trabajo, en las normas laborales del trabajo vigentes emanadas del Estado o en otros cuerpos normativos a que se remiten aquéllos, sea con la intención de infringir o con mera negligencia. Definición que revela que la falta laboral se compone de diversos elementos.

Es indispensable que previamente exista una tipificación de las obligaciones y prohibiciones que debe observar el trabajador en la ejecución de la relación de trabajo, como también de las faltas laborales. Tipificación que debe establecerse en el reglamento interno, en el reglamento de higiene y seguridad en el trabajo, en el contrato individual de trabajo, en el instrumento colectivo, en las normas estatales. También es posible que otros cuerpos normativos, tales como códigos de conductas, procedimientos internos, regulen obligaciones y prohibiciones que deben observar los trabajadores, lo que será legítimo en la medida que los cuerpos normativos antes señalados se remitan a éstos, otorgándole competencia para establecer normas de conducta.

La tipificación no es rígida, a diferencia de lo que ocurre en el Derecho Penal con la tipificación de los delitos, debido a que las normas no crean las faltas laborales, sino que solamente le permiten al trabajador conocer la conducta que deben desplegar y determina la correlación que debe existir entre las faltas laborales y la sanción aplicada. Por lo demás, muchas obligaciones se entienden implícitas, emanando de la naturaleza de los servicios y de la buena fe contractual. Asimismo, no puede obviarse que es prácticamente imposible predecir la totalidad de conductas que pueden atentar contra los intereses de la empresa, de ahí que sean lícitas las normas de conductas genéricas.

Debe tenerse presente que aun cuando se vulneren obligaciones y prohibiciones laborales, puede no configurarse la falta laboral si concurre una causal eximente, como lo puede ser la legítima defensa, al no ser antijurídico al actuar. Circunstancia que debe ser invocada y acreditada por el trabajador dependiente.

Debido a que el poder disciplinario opera en el contexto del contrato individual de trabajo, solamente deben establecerse obligaciones y prohibiciones que deba observar el dependiente en la jornada de trabajo o con ocasión de la prestación laboral, no pudiendo abarcar la conducta que el dependiente deba observar en su tiempo libre y vida privada, salvo que la conducta extralaboral afecte intereses de la empresa o le impida ejecutar el trabajo convenido al dependiente, caso en el cual es lícita la imposición de deberes respecto de la conducta extralaboral que afecta los intereses de la empresa. De este modo, la conducta extralaboral del trabajador dependiente por regla general no puede 
configurar una falta laboral, salvo cuando con la misma resulte lesionada la empresa misma o la posición contractual del trabajador, caso en que sí existe una falta laboral.

Como consecuencia de lo señalado en el párrafo anterior, la comisión de delitos fuera de la jornada de trabajo por parte del dependiente no configura una falta laboral, salvo cuando se afecta la organización productiva empresarial o sus intereses, lo que debe ser acreditado por el empleador.

Es posible que la conducta del trabajador dependiente configure simultáneamente una falta laboral y un delito. Debido a que la falta laboral se configura en forma independiente a la existencia de un delito, el empleador puede sancionar aquélla sin necesidad de esperar la condena penal con autoridad de cosa juzgada por la misma conducta, no resultando vulnerada la presunción de inocencia, la cual solamente opera en materia penal, más no en sede laboral. Esto es así, porque la responsabilidad disciplinaria laboral existe autónomamente de la responsabilidad penal, por tanto, aun cuando el trabajador sea absuelto en sede penal puede ser sancionado laboralmente por el empleador. La única excepción a esta regla es que la falta laboral contemple como requisito de existencia para su configuración la condena previa en sede penal, caso en el cual será necesario esperar una sentencia penal condenatoria con autoridad de cosa juzgada para sancionar laboralmente al dependiente.

La culpabilidad es un elemento de existencia de la falta laboral, por tanto, si no concurre no hay falta laboral. Al ser la sanción laboral con que se castiga la falta laboral una verdadera pena privada, que tiene un carácter punitivo, necesariamente debe concurrir la culpabilidad, de lo contrario, es imposible formularle un juicio de reproche al trabajador. En la generalidad de los casos es indiferente que concurra el dolo o la culpa, salvo que la normativa laboral exija una culpabilidad calificada, caso en el cual si no concurre no se configura la falta laboral.

\section{Bibliografía CitADA}

Assantı, Cecilia (1963): Le sanzioni disciplinari nel rapporto di lavoro (Milano, Giuffré).

BRÉGOU, Pierre (2012): Le pouvoir disciplinaire de l'employeur (París, Editions Liaisons).

CaAmaño Rojo, Eduardo (2004): "El bien jurídico protegido frente a los actos de acoso sexual en el lugar de trabajo", en Revista de Derecho de la Pontificia Universidad Católica de Valparaíso (Vol. XXV), pp. 93-114.

Caamaño Rojo, Eduardo; Carvajal Godor, Gabriela; Jiménez Trejo, Patricio (2005): El acoso sexual en la empresa: análisis de la Ley No 20.005 (Santiago, LexisNexis). 
CAAmaño Rojo, Eduardo (2008): "Las materias objeto de negociación colectiva y la libertad sindical: el fantasma de los 'Chicago Boys' a 30 años del Plan Laboral", en Revista de Estudios Laborales de la Sociedad Chilena de Derecho del Trabajo y de la Seguridad Social (№ 3), pp. 117-138.

CAamaño Rojo, Eduardo; Ugarte Cataldo, José Luis (2010): Negociación colectiva y libertad sindical: un enfoque crítico (Santiago, LegalPublishing).

CAAmaño Rojo, Eduardo (2013): "La sanción del acoso laboral: crónica de una mala ley con algunas buenas intenciones", en Revista Laboral Chilena (No 214), pp. 65-77.

CaAmaño Rojo, Eduardo; Ugarte Cataldo, José Luis (2014): "El acoso laboral: tutela y prueba de la lesión de los derechos fundamentales", en: Revista lus et Praxis (Año 20, No 1), pp. 67-90.

Camerlynck, Guillaume; Lyon-Caen, Gérard; Pélissier, Jean (1984): Droit du Travail (París, Dalloz).

Carcelén García, Javier (2001): Faltas y sanciones: el expediente disciplinario en la empresa (Madrid, FC Editorial).

Castro Arguelles, María Antonia (1993): El régimen disciplinario en la empresa. Infracciones y sanciones laborales (Pamplona, Aranzadi).

Congedutı, Mara (2011): "Il procedimento disciplinari: elementi, principi e eegole", en VV.AA., Licenziamenti e sanzioni nei rapporti di lavoro (Padova, Cedam), pp. 5-63.

Cremades SÁInz-PAStor, Bernardo (1969): La sanción disciplinaria en la empresa (Madrid, Instituto de Estudios Constitucionales).

Cruz Villalón, Jesús (2010): Compendio de Derecho del Trabajo (Madrid, Tecnos).

D’Avossa, Edoardo (1989): Il Potere disciplinare nel rapporto di lavoro (Milano, Ipsoa Informática).

Dı PAOLA, Luigi (2010): Il potere disciplinare nel lavoro privato en el pubblico impiego privatizzato (Milano, Guiffré Editore).

Fernández LóPez, María Fernanda (1991): El poder disciplinario en la empresa (Madrid, Editorial Civitas S.A.).

Fernández Toledo, Raúl (2014): “La configuración del poder disciplinario del empleador en el ordenamiento laboral nacional", en: VV.AA., Estudios de regulación empresarial (Santiago, LegalPublishing-Thomson Reuters), pp. 135-197.

Gaete Berríos, Alfredo (1967): Tratado de Derecho del Trabajo y Seguridad Social (Santiago, Editorial Jurídica de Chile).

Gamonal Contreras, Sergio; Prado López, Pamela (2009): El mobbing o acoso moral laboral, $3^{\text {a }}$ edición (Santiago, LegalPublishing). 
Gamonal Contreras, Sergio; Guidi Moggia, Caterina (2012): Manual del Contrato de Trabajo, $3^{\text {a }}$ edición revisada y actualizada (Santiago, LegalPublishing).

García PIÑEeIRO, Nuria (1997): "Consideraciones sobre la privación de libertad como causa de despido", en VV.AA., Cuestiones actuales sobre el despido disciplinario (Santiago de Compostela, Universidad Santiago de Compostela), pp. 65-74.

GIL y GIL, José Luis (1993): Autotutela privada y poder disciplinario en la empresa (Madrid, Centro de Publicaciones del Ministerio de Justicia).

Gómez Abelleira, Francisco Javier (2009): La causalidad del despido disciplinario (Madrid, Civitas S.A.).

IrURETA URIARTE, Pedro (2003): "Las organizaciones de tendencia ante el derecho", en Persona y Sociedad (Volumen XVII, № 2), pp. 235-248.

IrUReta Uriarte, Pedro (2011): "Vigencia del principio de la buena fe en el Derecho del Trabajo Chileno", en Revista lus et Praxis (Año17, № 2), pp. 133-188.

IrURETA URIARTE, Pedro (2012 a): "La prohibición de competencia y la buena fe contractual", en VV.AA. Estudios de Derecho del Trabajo y de la Seguridad Social (Santiago, LegalPublishing), pp. 59-116.

IRURETA URIARTE, Pedro (2012 b): "El estándar normativo de la injuria laboral", en Revista de Derecho de la Universidad Austral (Vol. XXV-No 2), pp. 83-109.

IRURETA URIARTE, Pedro (2013 a): "La ejecución de actos dañosos como fundamento de extinción del contrato de trabajo", en Revista de Derecho Universidad Católica del Norte (Año 20, № 2), pp. 179-206.

IrUReta Uriarte, Pedro (2013 b): "La configuración jurídica de las vías de hecho como causa del despido disciplinario", en Revista lus et Praxis (Año 19, № 2), pp. $179-206$.

IrUReta Uriarte, Pedro (2013 c): "Las inasistencias al trabajo como causa de terminación del contrato", en Revista de Derecho de la Universidad Austral (Vol. XXVI-N ${ }^{\circ}$ 2), pp. 39-65.

Koch Salazar, Carlos (2005): "Algunos alcances de la ley 20.005 sobre acoso sexual". Revista Laboral Chilena (No 136), pp. 83-87.

Lanata Fuenzalida, Gabriela (2004): "Regulación legal del acoso sexual. Análisis de la Ley 20.005", en Revista de Derecho Universidad de Concepción (No 215-216, año LXXII), pp. 83-104.

Lanata Fuenzalida, Gabriela (2010): Contrato Individual de Trabajo, $4^{\text {a }}$ edición actualizada (Santiago, LegalPublishing).

LAZZARI, Chiara (2012) "Il códice disciplinare", en VV.AA. Il potere disciplinare del datore di lavoro (Torino, UTET Giuridica), pp. 32-85.

LEGA, Carlo (1956): Il potere disciplinare del datore di lavoro (Milano, Giuffré). 
Lizama Portal, Luis; Ugarte Cataldo, José Luis (2005): Nueva ley de acoso sexual (Santiago, LexisNexis).

Lizama Portal, Luis (2003): Derecho del Trabajo (Santiago, Editorial LexisNexis).

Luer Gómez, Nicole (2013): Empresas de tendencia en Chile (Santiago, LegalPublishing).

LuJÁn AlCARAZ, José (1997): "Algunas reflexiones sobre el principio de proporcionalidad en la calificación del despido", en VV.AA., Cuestiones actuales sobre el despido disciplinario (Santiago de Compostela, Universidad Santiago de Compostela), pp. 23-32.

Luque Parra, Manuel (1999): Los límites jurídicos de los poderes empresariales en la relación laboral (Barcelona, J.M. Bosch Editor).

Macchiavello, Guido (1986): Derecho del Trabajo. El contrato individual y la relación de trabajo (Santiago, Fondo de Cultura Económica), tomo I.

MaINARDI, Sandro (2002): Il potere disciplinare nel lavoro privato e pubblico. Art. 2106 (Milano, Guiffré Editore).

MAINARDI, Sandro (2012): "Le sanzioni disciplinari conservative del rapporto di lavoro", en VV.AA. II potere disciplinare del datore di lavoro (Torino, UTET Giuridica), pp. 89-116.

MannaCio, Giorgo (2001): "Alcolismo e licenziamento per giusta causa", en II Lavoro nella Giurisprudenza (Vol. 9), pp. 832-835.

MANCINI, Giuseppe Federico (1957): La responsabilitá contrattuale del prestadore di lavoro (Milano, Giuffré).

Mazzotta, Oronzo (2011): Diritto del lavoro, quarta edizione (Milano, Giuffré Editore).

MegnonI, Luigi (1985): "I poteri dell' emprenditore", En VV.AA. Diritto e valori (Bolonia, Il Mulino), pp. 387-407.

MeLıs, Christian; SÁez, Felipe (2009): El contrato individual de trabajo en los dictámenes de la Dirección del Trabajo, $2^{a}$ edición (Santiago, LegalPublishing).

MonstuschI, Luigi (1973): Potere disciplinare e rapporto di lavoro (Milano, Giuffré).

MonstusCHI, Luigi (1991): "Potere disciplinare e rapporto di lavoro privato", en Quaderni Diritto Lavoro e Relazioni Industriali (No 9), pp. 9-26.

Montoya Melgar, Alfredo (1965): El poder de dirección del empresario (Madrid, Centro de Estudios Constitucionales).

Montoya Melgar, Alfredo (2014): Derecho del Trabajo, 45ª edición (Madrid, Tecnos).

Morato García, Rosa María (2011): Derecho de resistencia y ejercicio irregular del poder de dirección (Granada, Comares). 
MuñIz Fernández-Costales, Javier (2005): Poder disciplinario empresarial y proceso especial de impugnación de sanciones (Oviedo, Consejo Económico y Social del Principado de Asturias).

Olea, Manuel Alonso; Casas Bahamonde, María Emilia (2006): Derecho del Trabajo, 24ª edición (Madrid, Civitas S.A.).

Palavecino Cáceres, Claudio (2006): "El nuevo ilícito de acoso sexual en el Derecho del Trabajo chileno", en Revista de Derecho de la Universidad Austral (Vol. XIX, № 1), pp. 105-123.

Palavecino Cáceres, Claudio (2012): "El nuevo ilícito de acoso laboral en el Derecho del Trabajo chileno", en Revista Chilena de Derecho del Trabajo y de la Seguridad Social (Vol. 3, No 6), pp. 13-28.

Pérez Rey, Joaquín (2013): El despido disciplinario (Albacete, Editorial Bomarzo). Poquet Catalá, Raquel (2011): La actual configuración del poder disciplinario empresarial (Valencia, Tirant Lo Blanch).

Rivero LAmA, Juan (1986): Limitación de los poderes empresariales y democracia industrial (Zaragoza, Secretariado de Publicaciones, Universidad de Zaragoza).

Rodríguez-Piñeiro y Bravo-Ferrer, Miguel (1983): "No discriminación en las relaciones laborales", en VV.AA. Comentarios a las Leyes Laborales. El Estatuto de los Trabajadores (Madrid, Editorial Edersa), tomo IV, pp. 325-452.

Rodríguez Rodríguez, Emma (2008): El poder disciplinario y la negociación colectiva (Granada, Comares).

Sagardor, Juan; Gil y Gil, José Luis; Valle, José Luis (2006): Prontuario de Derecho del Trabajo, $8^{a}$ edición (Madrid, Civitas S.A.).

Sala Franco, Tomás (2003): "Los Principios de imperatividad legal, de norma mínima y de norma más favorable", en VV. AA. Los principios del Derecho del Trabajo (Madrid, Centro de Estudios Financieros), pp. 127-137.

SANTANA, Ricardo (2001): El poder disciplinario del empleador en la empresa privada (Montevideo, Fundación de Cultura Universitaria).

Spagnuolo Vigorita, Luciano (1972): "Il potere disciplinare dell' impeditore e i limiti derivanti dallo Statuto dei Lavoratori", en VV.AA. II potere dell' impeditore e i limiti derivanti dallo Statuto dei Lavoratori (Milano, Giuffré), pp. 49-65.

Spagnuolo Vigorita, Luciano; Ferraro, Giusepe (1975): "Art. 7 (Sanzioni disciplinari)", en VV.AA. Commentario dello Statuto dei Lavoratori. Tomo I. art. 1-18 (Milano, Giuffré), pp. 145-235.

SupPIE, María Giuseppe (1982): Il rapporto di lavoro: costituzione e svolgimento (Padova, CEDAM). 
Thayer, William; NovoA, Patricio (2010): Manual de Derecho del Trabajo, $4^{a}$ edición actualizada (Santiago, Editorial Jurídica de Chile), tomo IV.

Terradillos Ormaetxea, Edurne (2004): El poder disciplinario empresarial. Principios y garantías (Valencia, Tirant Lo Blanch).

Toledo Aldunate, Enrique (2006): El poder disciplinario del empleador. Tesis de Licenciatura en Ciencias Jurídicas y Sociales (Valparaíso, Facultad de Derecho Universidad Católica de Valparaíso).

Zangari, Guido (1971): Potere disciplinare e licenziamento (Milano, Giuffré).

Walker Errázuriz, Francisco; Arellano Ortiz, Pablo (2014): Derecho de las relaciones laborales. Un derecho vivo (Santiago, Librotecnia). 